\title{
Criação e Avaliação de Personas para Sistemas com foco em pessoas com Transtorno do Espectro Autista: Um Relato de Experiência sobre o uso de Netnografia
}

\author{
Creating and Evaluating Personas for Systems with a \\ Focus on People with Autistic Spectrum Disorders: An \\ Experience Report on the Use of Netnography
}

\author{
Anna Beatriz Marques, Gabriel Aires Melo, Victoria Gabriella Rebouças Pereira, \\ Patrícia Freitas Campos de Vasconcelos \\ Universidade Federal do Ceará (UFC) \\ Russas, Ceará - Brasil \\ \{beatriz.marques, patricia.vasconcelos\}@ufc.br, \{airesgabrielmelo15, \\ victoriagabriellaufc\} @gmail.com
}

\begin{abstract}
Netnography is an ethnography performed online, which has a reduced cost when compared to conventional ethnography and makes it possible to reach a dispersed target audience, such as people with Autism Spectrum Disorder (ASD). This paper reports the creation of personas and user requirements based on data obtained in a netnography conducted on the Instagram social network. To evaluate the quality of the personas created, we adopted two strategies: (i) a questionnaire with software development professionals to assess the level of completeness, willingness to use, clarity and empathy of the personas; and (ii) a focus group with members of a research project on ASD to explore the usefulness of personas for the design of products for autistic people. As a result of this analysis, four of the six personas created were rated as of excellent quality, the other two achieved medium quality.
\end{abstract}

Keywords. Persona; Autistic Spectrum Disorder; Netnography; Persona evaluation; Experience report.

Resumo. Netnografia é uma etnografia realizada online, que tem um custo reduzido quando comparada à etnografia convencional e possibilita o alcance de um público-alvo disperso, como é o caso das pessoas com Transtorno do Espectro Autista (TEA). Este artigo relata a criação de personas e requisitos de usuário com base em dados obtidos em uma netnografia conduzida na rede social Instagram. Para avaliar a qualidade das personas criadas, duas estratégias foram adotadas: (i) aplicação de questionário com profissionais da área de desenvolvimento de software para avaliar o nível de completude, disposição de uso, clareza e empatia das personas; e (ii) realização de grupo focal com integrantes de um projeto de pesquisa sobre TEA para explorar a utilidade das personas para a concepção de produtos para pessoas autistas.

Cite as: Marques, A.B.S., Melo, G.A., Pereira, V.G.R., \& Vasconcelos, PF.C. (2021). Creating and Evaluating Personas for Systems with a Focus on People with Autistic Spectrum Disorders: An Experience Report on the Use of Netnography (Criação e Avaliação de Personas para Sistemas com foco em pessoas com Transtorno do Espectro Autista: Um Relato de Experiência sobre o uso de Netnografia). iSys: Revista Brasileira de Sistemas de Informação (Brazilian Journal of Information Systems), Vol(num), pp-pp. DOI: xxxxxxxxxxxx 
Como resultado desta análise, quatro das seis personas criadas foram avaliadas como de ótima qualidade, as outras duas alcançaram qualidade média.

Palavras-Chave. Persona; Transtorno do Espectro Autista; Netnografia; Avaliação de persona; Relato de experiência.

\section{Introdução}

Boscarioli et al. (2017) apresentam como um dos Grandes Desafios de Pesquisa em Sistemas de Informação no Brasil (GranDSI-BR), a necessidade de investigar como ampliar a aproximação entre organizações e o ambiente externo para a oferta de melhores serviços e ao diálogo efetivo entre estas partes por meio de Sistemas de Informação (SIs). Segundo Uchoa e Coutinho (2018), as plataformas online e redes sociais estão promovendo um maior engajamento de participantes externos às equipes de desenvolvimento de software em seus processos. A imersão em comunidades de plataformas online permite a compreensão de opiniões, comportamentos e sentimentos de pessoas em relação a diversas tecnologias (Rodrigues et al., 2018; Fontão et al. 2017; da Silva et al., 2016). O conteúdo disponível e o acesso a pessoas de diferentes contextos nas redes sociais apresentam potencial para o seu uso como fonte de informação e criação de empatia no desenvolvimento de soluções tecnológicas (Marins e Miletto, 2015).

Neste contexto, a netnografia surge como um processo de imersão em plataformas digitais para investigar determinado público sem altos investimentos, como ocorre com estudos de campo (Melo e Abelheira, 2015). Além disso, a netnografia permite a imersão em comunidades e grupos geograficamente distribuídos, possibilitando a obtenção de dados em maior quantidade e qualidade. Tal fato motivou a adoção da netnografia em um projeto de desenvolvimento de tecnologias acessíveis para pessoas com Transtorno do Espectro Autista (TEA). A netnografia mostrou-se apropriada para a equipe de desenvolvimento por possibilitar o alcance a mais pessoas envolvidas com o TEA, quando comparado ao número de pessoas disponíveis na região em que o projeto é desenvolvido.

Este artigo é uma extensão de Marques e Aires (2020), artigo publicado no V Workshop sobre Aspectos Sociais, Humanos e Econômicos de Software. Marques e Aires (2020) apresentam um relato de experiência da equipe de desenvolvimento do projeto ProDTeA (Projeto e Desenvolvimento de Tecnologias Acessíveis) na adoção de netnografia para compreensão sobre o público-alvo e suas necessidades. A partir da netnografia, foi possível criar personas para representar diferentes perfis de usuários envolvidos com TEA e que possuem interesse em adotar tecnologias. As personas possibilitaram a identificação de um conjunto inicial de requisitos para tecnologias acessíveis a serem desenvolvidas pelo projeto.

A questão de pesquisa explorada neste artigo consiste em "Qual a percepção de profissionais de desenvolvimento de software e pesquisadores da área de autismo e tecnologia sobre a qualidade de personas relacionadas ao autismo criadas por meio da netnografia?". Nesta extensão, são apresentadas a condução e análise dos resultados da avaliação da qualidade das personas, a fim de analisar a viabilidade de uso dos artefatos obtidos para a concepção de novos produtos para pessoas autistas. A avaliação foi conduzida por meio do uso de questionários com 33 profissionais com experiência no desenvolvimento de software e grupo focal com quatro integrantes do ProDTeA, que não estavam envolvidos na condução da netnografia. 
Com este relato, espera-se demonstrar como a netnografia pode ser utilizada como suporte ao desenvolvimento de software, contribuindo com o GranDSI-BR de considerar uma visão sistêmica e socialmente consciente para SIs. Conforme discutido em Boscarioli et al. (2017), para a concepção e a adoção de uma visão sistêmica e socialmente consciente para SI, deve-se considerar as particularidades e padrões de comportamento de potenciais usuários, revisitando metodologias, teorias e técnicas adotadas pela comunidade de SI.

Este artigo está organizado da seguinte forma: a Seção 2 apresenta a fundamentação teórica. Na Seção 3 são apresentados os trabalhos relacionados. A Seção 4 descreve o relato de experiência. As personas e requisitos obtidos na netnografia são apresentados na Seção 5. A Seção 6 relata a avaliação das personas. As ameaças à validade identificadas durante esta pesquisa são descritas na Seção 7. Por fim, na Seção 8 são apresentadas as conclusões e trabalhos futuros.

\section{Fundamentação Teórica}

Nesta seção serão apresentados conceitos necessários para a melhor compreensão do relato de experiência: Transtorno do Espectro Autista, netnografia e personas.

\subsection{Transtorno do Espectro Autista (TEA)}

O Transtorno do Espectro Autista (TEA) é um transtorno do neurodesenvolvimento que tem como principais características o prejuízo na comunicação e interação social, comportamentos repetitivos e padrões restritos de interesses ou atividades (APA, 2014). O estágio em que o TEA fica evidente varia de acordo com o paciente, geralmente os sintomas estão presentes desde o início da infância.

Segundo a APA (2014) há três níveis de gravidade para o TEA: Nível 1 (Exige apoio) - apresentam dificuldades para iniciar interações sociais, respostas atípicas, parecem apresentar interesse reduzido por interações sociais além de inflexibilidade de comportamento e dificuldade em trocar de atividade; Nível 2 (Exige apoio substancial) apresentam déficits graves nas habilidades de comunicação social verbal e não verbal, limitações em dar início a interações sociais e respostas reduzidas ou anormais a aberturas sociais que partem de outros; Nível 3 (Exige apoio muito substancial) - apresentam déficits graves nas habilidades de comunicação social verbal e não verbal, grandes limitações em dar início a interações sociais e respostas mínimas a aberturas sociais que partem de terceiros, podem apresentar fala inteligível.

Ainda existe preconceito e falta de informação sobre TEA, principalmente em regiões menos desenvolvidas, como a região em que o projeto ProDTeA é desenvolvido: no município de Russas, no interior do Ceará. Isso ocasiona dificuldade em envolver pais, mães e responsáveis em pesquisas de campo, pois muitos preferem não falar sobre o assunto ou não buscam tratamento adequado. Em razão desses fatores, a netnografia apresentou-se como uma alternativa adequada para o projeto, uma vez que nas redes sociais observa-se diversos perfis de pais, mães e profissionais relacionados ao TEA que compartilham experiências diárias.

\subsection{Netnografia}

A netnografia consiste em uma variação da etnografia que, por sua vez, segundo Brewer (2000), é o estudo de pessoas em ambientes ou campos naturais por meio de métodos de 
coleta de dados que capturam seus significados sociais e atividades cotidianas. A etnografia envolve o pesquisador que participa diretamente no ambiente, mas não nas atividades das pessoas investigadas, a fim de coletar dados de uma forma sistemática, mas sem que lhes seja imposto um significado externo.

De acordo com Kozinets (2014), a netnografia descreve a aplicação das práticas da etnografia em um ambiente online para a obtenção de informações para uma determinada finalidade. A netnografia pode ser aplicada para levantamento de dados para marketing, pesquisas científicas, obtenção do feedback de usuários e auxílio na criação de produtos. A técnica apresenta vantagens como o baixo custo, alto alcance e a possibilidade de aplicar métodos externos às suas etapas para complementação (Melo e Abelheira, 2015). Nesta pesquisa, a netnografia mostrou-se apropriada por (i) possibilitar o alcance a mais pessoas envolvidas com o TEA, quando comparado ao número de pessoas disponíveis na região em que o projeto é desenvolvido; e (ii) permitir a análise de dados disponíveis em redes sociais, onde diversos usuários compartilham conhecimentos e experiência sobre o TEA.

Os passos e diretrizes sugeridas para a execução da netnografia (Kozinets, 2014) são: planejamento, imersão e garantia de preceitos éticos, coleta de dados, análise de dados e obtenção de artefatos requeridos.

Planejamento: definição do foco da pesquisa, artefatos a serem gerados, públicoalvo da pesquisa, plataforma online, abordagens para coleta de dados. É necessário limitar o público-alvo para o escopo não ficar muito extenso, pois em ambientes online, lida-se com uma enorme quantidade de dados, o que os torna mais quantitativos do que uma etnografia clássica. Entre as abordagens que podem ser efetuadas em um ambiente online pode-se citar: entrevistas, formulários online, chats, fóruns, questionários, videoconferência, brainstorming em grupos online, avaliação de protótipos e observação.

Imersão e garantia de preceitos éticos: ao estabelecer o primeiro contato com o público-alvo, é necessário apresentar-se, explicar a motivação do seu estudo e da sua abordagem e solicitar autorização para a coleta e análise de dados por meio de termo de consentimento livre e esclarecido.

Coleta de dados: coleta manual ou automática de dados por meio das abordagens selecionadas, organização e catalogação para posterior análise.

Análise de dados: após a coleta de dados, os dados obtidos são analisados e organizados para posterior uso na produção dos artefatos.

Obtenção de artefatos requeridos: no contexto de desenvolvimento de software, os dados analisados podem ser usados pela equipe de desenvolvimento de software para delineamento de perfis de usuário, definição de personas, avaliação da experiência do usuário, levantamento de requisitos, entre outros.

\subsection{Personas}

Personas são representações fictícias de um usuário típico de um sistema com informações baseadas em dados coletados do público-alvo (Barbosa, 2010). Cada persona possui os dados pessoais (nome, profissão, idade), perfil (o que gosta de fazer, objetivos), os requisitos que ela precisa para o sistema, as expectativas, habilidades entre outras informações. As informações contidas nas personas dependem do objetivo para o qual 
está sendo utilizada. Podem ser criadas mais de uma persona para um mesmo objetivo, uma do sexo masculino e uma do sexo feminino, por exemplo.

Pinheiro et al. (2018) realizaram um estudo experimental aplicando a técnica de proto-persona para a obtenção de requisitos de experiência do usuário. Uma protopersona é um protótipo de persona que une informações sobre o usuário final e o domínio de software, explorando as seguintes informações: dados demográficos, objetivos e necessidades, comportamentos e preferências, dificuldades. A Figura 1 apresenta a protopersona Ana Luiza, uma criança autista do sexo feminino, 8 anos, que mora em Fortaleza. Ana Luiza é diagnosticada com o TEA nível 2 (moderado). A proto-persona explora seus comportamentos, necessidades e objetivos.

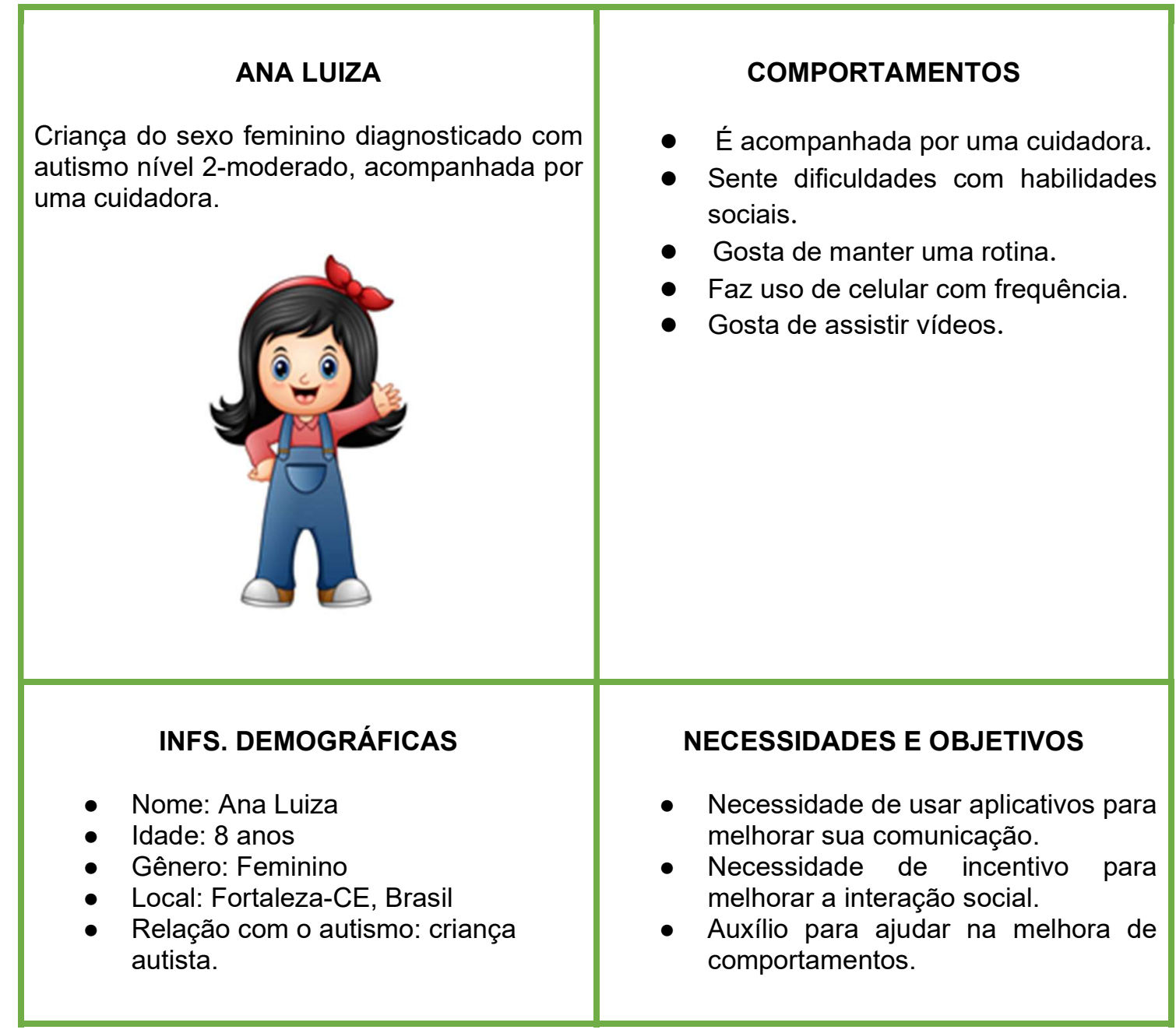

Figura 1. Persona criada com a técnica proto-persona.

Ferreira et al. (2018) propõem uma técnica para o desenvolvimento de personas baseado no mapa de empatia, denominada PATHY (Personas EmpATHY). A técnica objetiva criar personas úteis para a identificação de requisitos de software por meio do fornecimento de um template com questões sobre quem é a persona, contexto no qual a persona vive, experiências prévias/preferências sobre tecnologias, problemas/necessidades/desejos que podem ser solucionados com uma nova tecnologia e soluções existentes. A Figura 2 ilustra a persona Clarisse criada seguindo o template 
fornecido pela técnica PATHY. A persona explora o contexto da vida acadêmica de Clarisse, descreve os principais problemas e necessidades de Clarisse em relação às suas atividades acadêmicas, assim como sua experiência com tecnologias existentes.

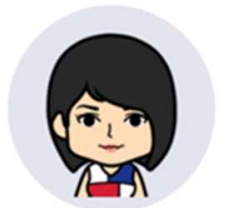

NOME: Clarisse

IDADE: 50 anos

\section{QUEM}

Clarisse é professora universitária, possui mestrado em Eng. Civil e se descreve como uma pessoa organizada, impaciente e com baixa visão. Uma de suas principais preocupações é de que não consiga acompanhar os avanços tecnológicos do meio onde vive, pois não nasceu na era tecnológica e isso, às vezes se torna um problema.

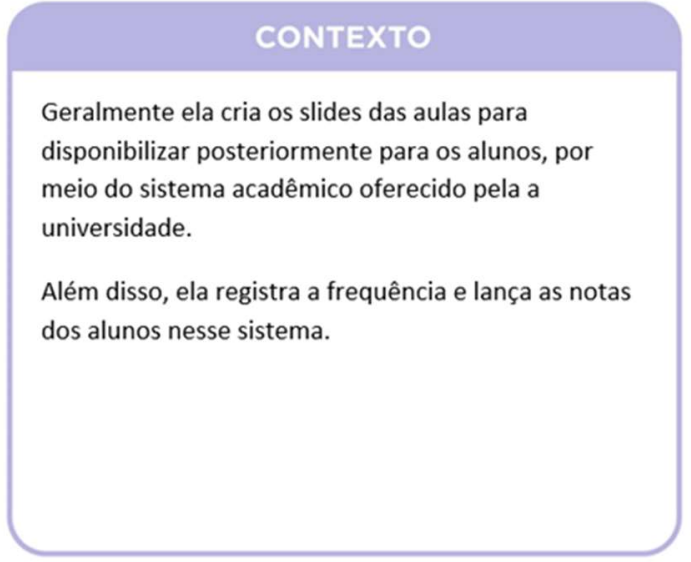

PROBLEMAS/NECESSIDADES/DESEJOS

P1: Possui dificuldades em usar funcionalidades do sistema no qual não são usadas com tanta frequência, pois acaba esquecendo os passos necessários para realizar as ações.

P2: O sistema a ser projetado poderia fornecer feedbacks sobre as ações que estão sendo executadas, além disso, ter a opção de deixar as letras maiores, para facilitar a visualização.

\section{EXPERIÊNCIAS PRÉVIAS/PREFERÊNCIAS}

E1: Ela gosta mais da parte de lançamento de frequências

E2: Ela não gosta da parte de compartilhamento de arquivos com os alunos, pois precisa preencher alguns campos que para ela são desnecessários e, além disso, não há feedback após o envio do arquivo. E3: Geralmente utiliza nas versões web e mobile. E4: Lendo manuais.

E5: Prefere passo a passo

E6: Ela prefere ver imagens, pois ajuda a memorizar. E7: Prefere se manter reservada.

\section{SOLUÇÕES EXISTENTES}

S1: Sim, o SIGAA, pois auxilia no gerenciamento acadêmico por meio das diversas funcionalidades disponibilizadas.

S2: Facilidade na realização de frequência dos alunos e lançamento de notas.

S3: Possui pouca usabilidade e algumas

funcionalidades são complexas para serem executas com sucesso.

Figura 2. Persona criada com a técnica PATHY (Oliveira Junior et al. 2020).

Neste relato, as informações requeridas nas personas PATHY e proto-personas foram integradas para definir os dados de interesse na etapa de coleta de dados.

\section{Trabalhos Relacionados}

Nesta seção serão apresentados resumidamente trabalhos relacionados à adoção de netnografia no desenvolvimento de software, uso de plataformas online e redes sociais em pesquisa de Engenharia de Software e avaliação da qualidade de personas. Para obtenção de trabalhos relacionados a essa pesquisa foram adotadas três estratégias: (i) busca automática na Scopus com a string de busca: ("social media" OR "social networks") AND ("autism" OR "autism spectrum disorder" OR "asd" OR "autistic") AND 
("user experience" OR "user evaluation" OR "netnography" OR "online ethnography"); (ii) análise dos anais do WASHES para identificação de trabalhos sobre uso de plataformas online e redes sociais em Engenharia de Software.

\subsection{Adoção de netnografia no contexto de desenvolvimento de software}

Marins e Miletto (2015) relatam o uso de netnografia no ensino de Design Thinking em uma disciplina de empreendedorismo. Os alunos organizados em seis equipes conduziram netnografia utilizando o Facebook, Skype e Whatsapp. Com os dados obtidos, os alunos: (1) construíram mapas de empatia para compreender os usuários; (2) construíram modelos de negócios; e (3) elaboraram protótipos para obter feedback dos usuários que participaram da netnografia. Os autores concluíram que a netnografia configurou uma valiosa fonte de informações aos alunos, que desenvolveram empatia com os usuários. Além disso, a interação entre os alunos e os envolvidos na pesquisa foi um processo colaborativo de aprendizagem, estimulando ideias criativas e inovadoras.

Rodrigues et al. (2018) adotaram a netnografia na avaliação de um aplicativo de monitoramento de controle menstrual. A netnografia foi aplicada em grupos sobre a saúde da mulher no Facebook. Por meio da observação de postagens, as autoras identificaram dados sobre: dúvidas sobre o aplicativo, problemas de interação, indicação de aplicativos, ausência de requisitos, erros de previsão, elogios, entre outros. As autoras afirmaram que a netnografia permitiu obter dados sobre a utilização do aplicativo no contexto de saúde da mulher, enriquecendo a avaliação do ponto de vista da experiência do usuário.

Rotman et al. (2012) levantaram desafios e estratégias para a netnografia efetiva em ambientes online de grande escala. Os autores identificaram cinco desafios: tamanho e escopo do ambiente de pesquisa; unidade de análise; estrutura da interface; conteúdo, ferramentas e instabilidade da plataforma; questões éticas. Como estratégias para tratar esses desafios, os autores apontam o uso combinado de diferentes metodologias, análise estrutural e processamento de linguagem natural.

De forma similar a Marins e Miletto (2015) e Rodrigues et al. (2018), este artigo relata a adoção de netnografia, porém a netnografia foi adotada em um projeto sobre tecnologias acessíveis para pessoas autistas. Assim como Rotman et al. (2012), este relato também permitiu identificar lições aprendidas sobre o uso da netnografia.

\subsection{Uso de plataformas online e redes sociais por pesquisadores e profissionais de Engenharia de Software}

Da Silva et al. (2016) apresentam um processo para análise de papéis de atores e suas relações em um ecossistema de software por meio de uma plataforma online. Por ser uma plataforma de domínio público, a identificação dos atores se deu por meio da equipe de desenvolvimento da plataforma e não diretamente na plataforma. A coleta de dados ocorreu por meio de entrevistas. Fontão et al. (2017) exploraram a experiência de desenvolvedores no desenvolvimento de aplicativos móveis por meio da mineração de dados sobre questões e respostas postadas no Stack Overflow. Os autores apontam que os resultados podem auxiliar na definição de estratégias para um maior engajamento dos desenvolvedores nos diversos ecossistemas de desenvolvimento mobile. Uchoa e Coutinho (2018) propõem a investigação de estratégias para o desenvolvimento colaborativo de jogos por meio de plataformas digitais. Os autores investigam a integração de crowdsourcing no desenvolvimento e manutenção de jogos digitais. 
No contexto de pesquisas sobre TEA, Saha e Agarwal (2015) realizaram um estudo para demonstrar como as comunidades online de autistas se apoiam. Os autores utilizaram a lista de blogs mais influentes disponibilizada pela organização Autism Speaks e analisaram blogs de mães de crianças autistas (13), pais de crianças autistas (10), grupos de autismo (13) e blogueiros autistas (4) entre os anos de 2009 e 2014. Os autores constataram que a comunidade de autistas oferece um maior suporte, tanto emocional quanto ao compartilhamento de conhecimento em relação a outras comunidades como câncer de mama e transtornos alimentares. Beykikhoshk et al. (2015) realizaram uma pesquisa para investigar como a rede social Twitter poderia ser empregada como fonte de mineração de dados para instruir a população afetada pelo TEA. Os tweets foram coletados e submetidos a pré-processamento, análise de conteúdo e classificação. Os resultados demonstraram que os tweets são ricos em informações sobre a rotina e o autismo, com alto valor informativo.

Os trabalhos mencionados adotam plataformas online e redes sociais para diferentes fins relacionados ao desenvolvimento de software. Este artigo propõe o uso da rede social Instagram em uma pesquisa baseada em netnografia, no contexto de um projeto de desenvolvimento de tecnologias acessíveis para pessoas com TEA.

\subsection{Avaliação de personas}

O uso de personas possibilita uma maior compreensão das características de um públicoalvo e pode ser considerada como um modelo mental dos usuários, mantendo a equipe focada em suas características (Nielsen e Hansen, 2014). Contudo, um dos desafios em relação à adoção e uso de personas é a dificuldade em avaliar sua acurácia e utilidade para cenários reais. Para contribuir com a avaliação de personas, Salminen et al. (2020) propuseram um instrumento denominado Personas Perception Scale (PPS) que considera fatores relevantes sobre a percepção de personas: consistência, completude, disposição de uso, credibilidade, clareza, similaridade, simpatia e empatia. Os fatores são avaliados por meio de uma escala de concordância. Salminen et al. (2020) argumentam que os pesquisadores podem selecionar os fatores de seu interesse para adaptar o instrumento a ser adotado em suas avaliações de personas.

O instrumento PPS foi adotado por Branco et al. (2020) para avaliar a percepção sobre a credibilidade, similaridade e empatia de quatro personas de alunas de cursos de Computação, do ponto de vista das próprias alunas que forneceram os dados para a criação das personas. As personas foram criadas com base em clusterização sobre os dados obtidos de um survey com as alunas dos cursos de Computação. O PPS foi adotado para realizar um pré-teste das personas, antes de sua adoção pela equipe de um projeto que visa definir iniciativas para o fortalecimento da participação feminina na área de Computação. Os resultados confirmaram que as personas representavam a realidade do público-alvo que pretendiam descrever.

Silva et al. (2021) conduziu um estudo comparativo sobre a qualidade de personas geradas de forma manual e automática com base em dados reais de crianças autistas. Os fatores de completude, disposição de uso, clareza e empatia do instrumento PPS foram adotados para avaliar a qualidade das personas do ponto de vista de profissionais e pesquisadores da área de saúde e educação relacionados ao TEA. Os resultados demonstraram que as personas geradas pelas diferentes abordagens obtiveram níveis de qualidade similares em relação aos fatores avaliados. 
De forma similar à Branco (2020) e Silva et al. (2021), esta pesquisa adaptou o instrumento PPS, proposto por Salminen et al. (2020) para avaliar as personas criadas com base nos dados obtidos da netnografia. Complementarmente, com o intuito de explorar a utilidade das personas e possíveis sugestões de melhorias, um grupo focal com integrantes do ProDTeA foi conduzido.

A Tabela 1 fornece uma visão resumida e comparativa dos trabalhos relacionados descritos nesta seção. Os seguintes critérios foram adotados para a comparação entre os trabalhos relacionados: (C1) adoção de netnografia, (C2) pesquisa em redes sociais/plataformas online, (C3) foco no público relacionado ao TEA e (C4) avaliação da qualidade de personas. Na última linha da Tabela 1 , observa-se que esta pesquisa atende a todos os critérios estabelecidos, diferenciando-se dos demais.

Tabela 1. Comparação entre trabalhos relacionados e esta pesquisa.

\begin{tabular}{|l|l|l|l|l|}
\hline Trabalho relacionados & C'l & C2 & C3 & C4 \\
\hline Marins e Miletto (2015) & Sim & Sim & Não & Não \\
\hline Rodrigues et al. (2018) & Sim & Sim & Não & Não \\
\hline Rotman et al. (2012) & Sim & Não & Não & Não \\
\hline Da Silva et al. (2016) & Não & Sim & Não & Não \\
\hline Fontão et al. (2017) & Não & Sim & Não & Não \\
\hline Uchoa e Coutinho (2018) & Não & Sim & Não & Não \\
\hline Saha e Agarwal (2015) & Não & Sim & Sim & Não \\
\hline Beykikhoshk et al. (2015) & Não & Sim & Sim & Não \\
\hline Salminen et al. (2020) & Não & Não & Não & Sim \\
\hline Branco et al. (2020) & Não & Não & Não & Sim \\
\hline Silva et al. (2021) & Não & Não & Sim & Sim \\
\hline Esta pesquisa & Sim & Sim & Sim & Sim \\
\hline
\end{tabular}

\section{Aplicação da netnografia no projeto ProDTeA}

Nesta seção serão descritas as etapas adotadas para a aplicação da netnografia no projeto ProDTeA. A Figura 3 ilustra as etapas, que são descritas a seguir. 


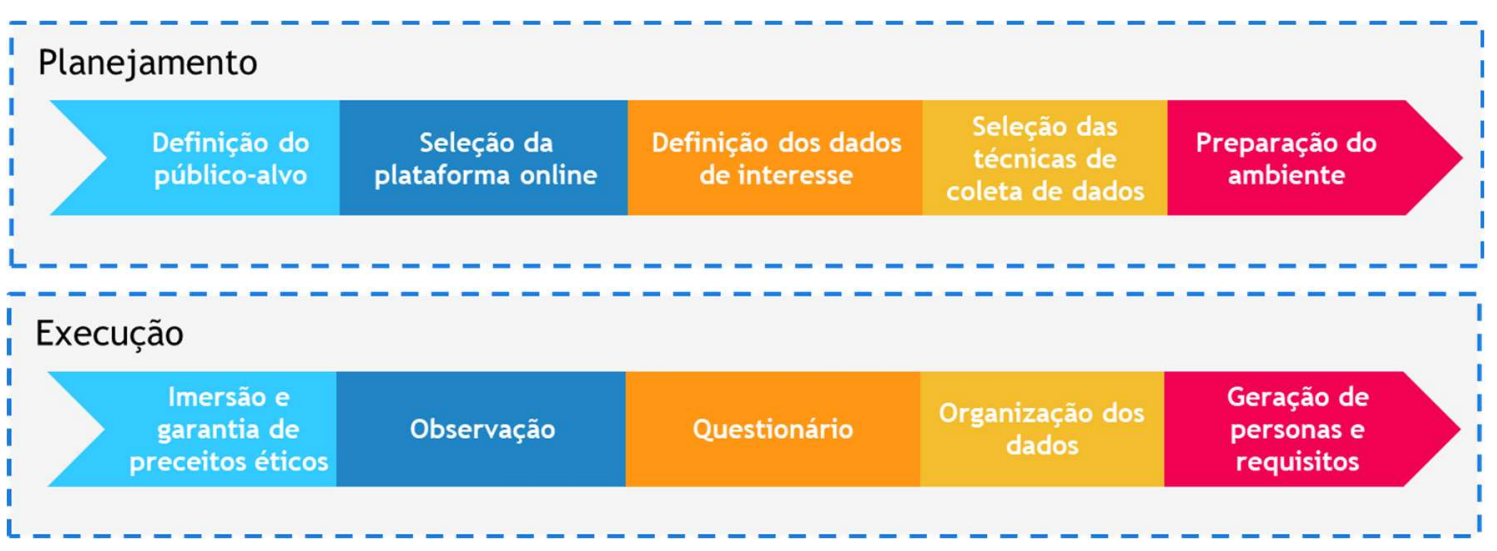

Figura 3. Etapas adotadas na condução da netnografia

\subsection{Planejamento}

Definição do público-alvo: o projeto ProDTeA visa desenvolver tecnologias acessíveis para pessoas com TEA. Logo, o público-alvo da netnografia consiste em pessoas afetadas pelo TEA: pessoas autistas; pais, mães e/ou responsáveis por pessoas com TEA; e profissionais que atuam em intervenções sobre o TEA.

Seleção da plataforma online: o projeto possui uma conta na rede social Instagram, onde são compartilhadas pesquisas e ações desenvolvidas. Observou-se que perfis de pessoas afetadas pelo TEA e instituições passaram a seguir a conta. Com isso, optou-se por conduzir a netnografia no Instagram. Não foram encontrados trabalhos relacionados que aplicassem netnografia com este público-alvo no Instagram.

Definição dos dados de interesse: para os perfis de pais, mães e profissionais relacionados ao TEA, foram estabelecidos como dados de interesse o nome completo, o gênero, a relação com o autismo, a região, a cidade, o estado, o nome do perfil no Instagram, a escolaridade, a profissão, as dificuldades observadas na interação dos autistas com tecnologias, as melhorias desejadas e se acreditam que a tecnologia pode ser uma boa aliada ao desenvolvimento e aprendizado dos autistas. Para os perfis de autistas, buscou-se identificar a idade, o nível de autismo, se possuía diagnóstico profissional, se possui experiência com tecnologia, quais plataformas (smartphone, tablet, computador...), quais os aplicativos/sites mais utilizados, preferências e atividades que praticam.

Seleção das técnicas de coleta de dados: observação das postagens dos perfis de interesse e aplicação de questionário online para complementar dados não identificados por meio da observação. O segundo autor deste relato foi responsável pela realização dessas atividades.

Preparação do ambiente: previamente à execução da netnografia, a equipe decidiu: (1) atrair o público-alvo por meio de novas postagens sobre o projeto e (2) buscar e seguir perfis de interesse para a netnografia.

\subsection{Execução}

Imersão e garantia de preceitos éticos: um membro da equipe realizou a abordagem inicial aos perfis de interesse (pessoas com TEA, pais ou responsáveis por pessoas com TEA, cuidadores de crianças autistas e profissionais interessados em contribuir com tema autismo), enviando via direct, uma pequena apresentação sobre o projeto e o objetivo da 
pesquisa, juntamente com um link para acesso ao Termo de Consentimento Livre e Esclarecido (TCLE) no Google Forms. Caso a pessoa aceitasse participar da pesquisa, deveria indicar no formulário e fornecer dados iniciais: o nome da conta no Instagram, a relação com o autismo e a localização (cidade, estado e região).

Esta etapa foi realizada com aproximadamente, 150 perfis de interesse. Obteve-se 32 respostas de aceite ao TCLE. Destas, somente 30 puderam ser utilizadas, pois duas não foram preenchidas corretamente, não permitindo a identificação do perfil no Instagram. Dos respondentes considerados, 27 eram mulheres e 3 eram homens. Sobre sua relação com o autismo (Figura 4), 66.7\% eram mães de autistas, 13.3\% eram profissionais e os demais eram cuidadores, autistas ou pais de autistas. Participaram pessoas de todas as regiões do Brasil, sendo a maioria do Nordeste (33.3\%) e Sudeste $(30 \%)$. Duas pessoas não residiam no Brasil, mas eram brasileiras.
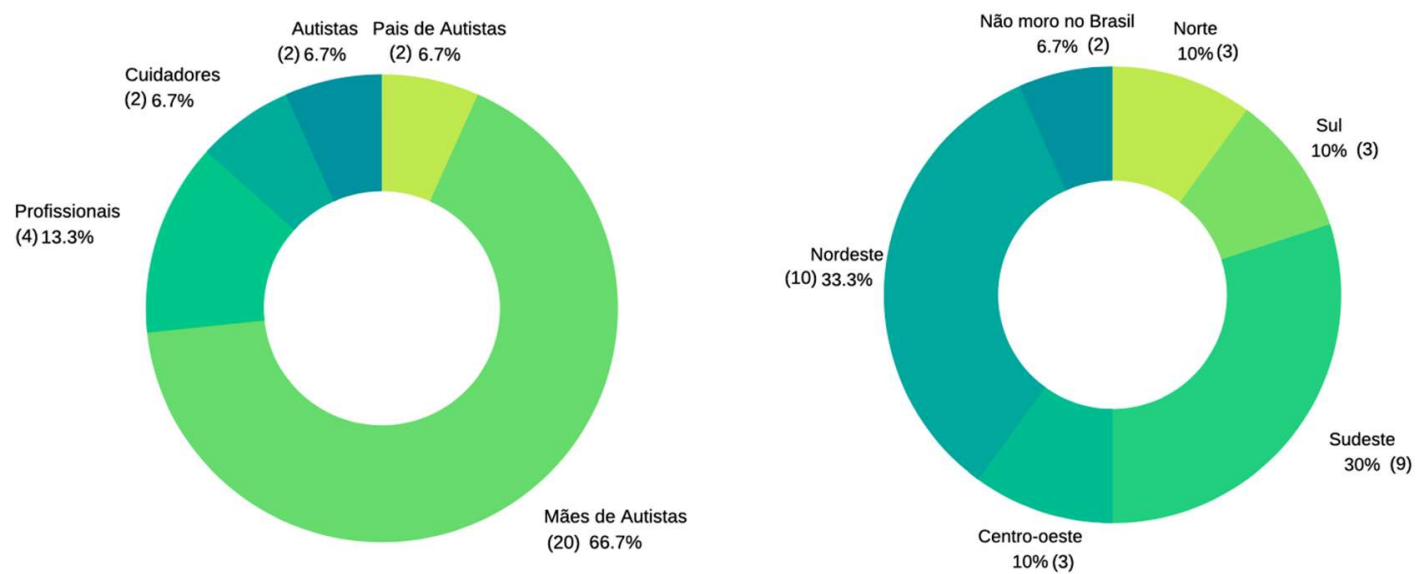

Figura 4. Caracterização dos participantes da netnografia

Observação: um membro da equipe elaborou uma ficha de extração (Figura 5) para guiar a coleta de dados e validou com a equipe para melhorias. A ficha continha os dados de interesse a serem coletados. Durante a observação, foram consideradas as últimas 50 postagens de cada perfil, além dos stories fixados nos destaques. Ao final da observação, nem todos os campos da ficha de extração foram preenchidos, pois não haviam informações suficientes nas postagens. Para complementá-las, prosseguiu-se para a aplicação de um questionário online.

Questionário: o link para o questionário online no Google Forms foi enviado por meio do direct para os perfis que haviam consentido com a pesquisa e sido submetidos à observação. O questionário foi direcionado a extrair dados sobre a experiência do autista com tecnologia, pois este tipo de informação não era comum nas postagens dos perfis. $\mathrm{O}$ questionário continha duas seções as questões serão apresentadas na Tabela 2: 


\begin{tabular}{|l|l||l|l|}
\hline \multicolumn{2}{|c|}{ Perfil $<$ N } & \multicolumn{2}{|c|}{ Sobre o autista: } \\
\hline Gênero: & & \\
\hline Relação com o autismo: & & Nível: & \\
\hline Região: & & Possui diagnóstico: & \\
\hline Quantidade de postagens: & & $\begin{array}{l}\text { Possui experiência com } \\
\text { tecnologia: }\end{array}$ & \\
\hline Destaques nos stories: & & Se sim, quais plataformas: & \\
\hline Tipo (profissional): & & $\begin{array}{l}\text { Sites e aplicativos mais } \\
\text { utilizados: }\end{array}$ & \\
\hline Data de extração: & Observação: \\
\hline
\end{tabular}

Figura 5. Ficha de extração utilizada na observação

As fichas de extração foram complementadas com as informações coletadas por meio do questionário. Um vídeo de agradecimento foi enviado visando uma aproximação entre o pesquisador e os participantes.

Tabela 2. Questões do questionário adotado na netnografia.

Sobre o autista

1. Qual a idade? Possui diagnóstico de autismo? Qual o nível de autismo?

2. Possui experiência com tecnologia? (computador, smartphones, tablets...) Se sim, com qual(is)? Quais sites e aplicativos mais utiliza?

3. Como é a interação do autista com essas tecnologias?

4. Quais as dificuldades encontradas ao utilizar os aplicativos/sites?

5. Quais melhorias observadas, que poderiam tornar essas tecnologias mais acessíveis?

Sobre os responsáveis, cuidador ou profissional:

6. Qual sua profissão/escolaridade?

7. Você acredita que a tecnologia pode ajudar no desenvolvimento e aprendizado de pessoas com TEA? Se sim, de que forma?

Organização dos dados: as fichas de extração foram separadas em grupos por categoria (pai de autista, mãe de autista, cuidador(a), profissional e autista) no intuito de facilitar a criação das personas.

Criação de personas: os dados das fichas de extração foram a base para geração de personas. As técnicas PATHY e proto-personas foram adotadas como base para a definição das informações das personas. As personas possuem três campos: (i) perfil, (ii) biografia e (iii) autismo e tecnologia.

O campo "perfil" foi baseado nos campos "quem" da PATHY e "dados demográficos" da proto-persona e contém os dados: idade, gênero, local, relação com o autismo. Estes dados foram obtidos do TCLE e da tabela "perfil" da ficha de extração.

O campo "autismo e tecnologia" foi baseado nos campos "comportamentos e preferências", "objetivos e necessidades" e "dificuldades" da proto-persona e nos campos "experiências prévias/preferências" e "problemas/necessidades/desejos" da PATHY. Para pessoas relacionadas ao autismo, este campo descreve a opinião sobre como estas 
pessoas vêem a interação dos autistas com a tecnologia, dificuldades observadas e melhorias que esperam para que a interação dos autistas melhore. Estes aspectos são explorados no questionário (questões 3, 4 e 5) e no campo "observação" da ficha de extração. Para as personas de autistas, este campo contém uma descrição de sua experiência com tecnologia, além de suas preferências e gostos. Estas informações foram obtidas da tabela "sobre o autista" e do campo "observação", ambos da ficha de extração, assim como das questões 2 e 3 do questionário.

No campo "biografia" há uma breve descrição da persona, com informações obtidas da observação e especificamente para as personas relacionadas ao autismo (pais, profissionais e cuidadores), também considerou-se a questão 6 do questionário, que aborda a profissão/escolaridade do respondente.

A Figura 6 mostra um mapeamento dos perfis cujas fichas de extração foram utilizadas para a geração de cada persona. As personas serão descritas na seção de resultados.

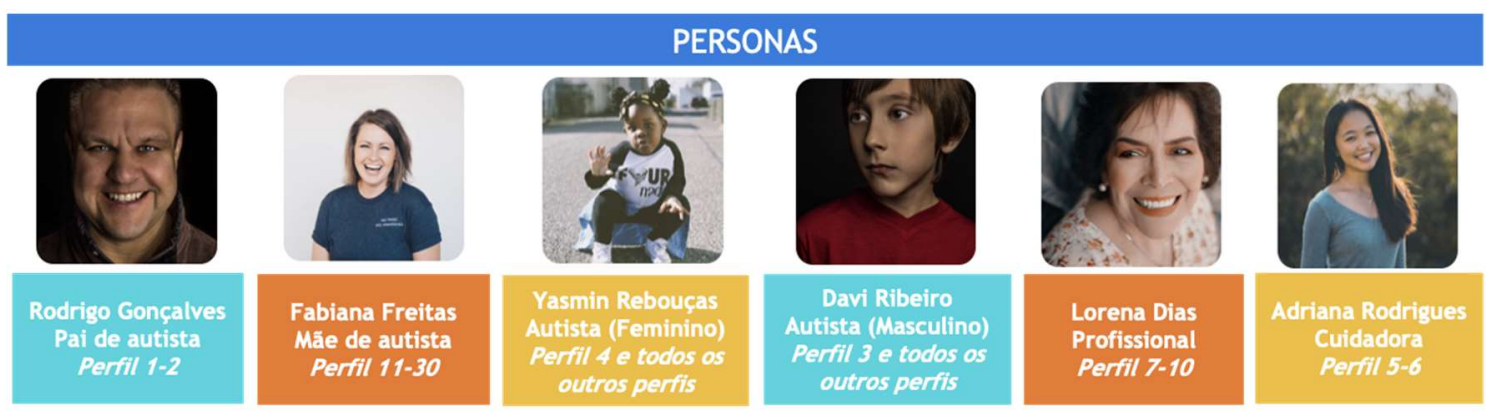

Figura 6. Mapeamento de perfis geradores de cada persona

Extração de requisitos: para extrair os requisitos, foi utilizado o campo "autismo e tecnologia" das personas, pois continha as necessidades, dificuldades, melhorias esperadas e preferências do uso de tecnologia pelos autistas. A Figura 7 ilustra o mapeamento do campo das personas utilizado para elicitar os requisitos. Os requisitos obtidos serão descritos na seção de resultados.

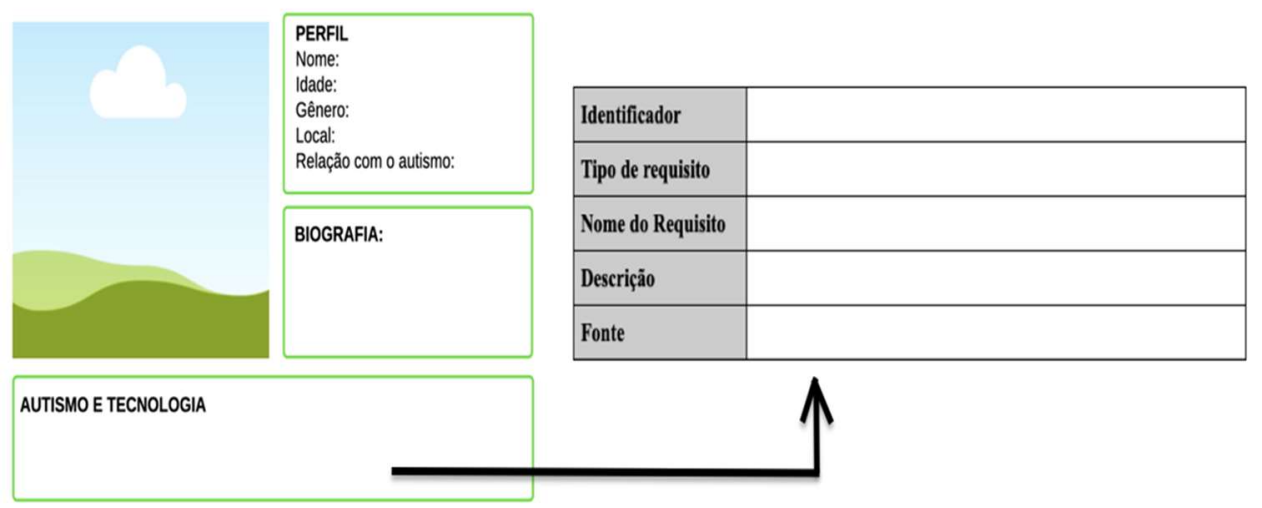

Figura 7. Indicação do campo utilizado para obter requisitos das personas 


\section{Resultados da netnografia}

Nesta seção serão apresentadas as personas e requisitos de usuário obtidos a partir da netnografia e análise dos dados obtidos.

\subsection{Personas}

O nome e sobrenome das personas são fictícios e não condizem com nenhum dos participantes da pesquisa. As imagens utilizadas nas personas são de uma plataforma de fotos livres de direitos autorais chamada Unsplash e as personas foram criadas utilizando a ferramenta Canva.

Para gerar a persona da mãe de um autista (Figura 8) foram analisadas as fichas de extração de 20 perfis de mãe. A persona criada foi nomeada como Fabiana Freitas, mãe de duas crianças autistas, com 3 e 9 anos de idade. Fabiana possui formação em Letras e incentiva seus filhos a usarem tecnologia, em especial jogos de associações que possam auxiliar a desenvolver habilidades motoras. Para Fabiana, recursos de personalização são importantes nas tecnologias, assim como a portabilidade para serem acessíveis em diferentes ambientes.

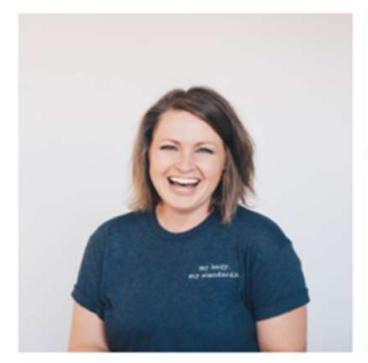

PERFIL

Nome: Fabiana Freitas

Idade: 35 anos

Gênero: Feminino

Local: Gurupi - TO, Brasil
Relação com o autismo: Mãe de autista

BIOGRAFIA:

Fabiana é mãe de dois filhos autistas, um de 3 e um de 9 anos. Formada em letras. Incentiva muito seus filhos a jogarem jogos de associaçōes para o desenvolvimento e melhoria da coordenação motora

\section{AUTISMO E TECNOLOGIA}

Fabiana acredita que a tecnologia é um ótimo auxilio para o aprendizado na alfabetização porque a tecnologia pode aumentar o interesse das crianças nesses assuntos e podem ter personalizaç̃o de acordo com o desenvolvimento de criança, além da poritiol

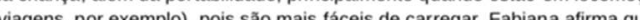
mesmo sendo um ótimo auxílio não deve-se expor muito as crianças à tecnologia pois pode causar dependência.

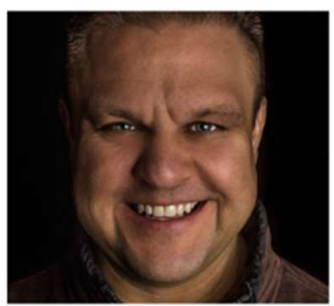
PERFIL Idade: 42 anos Gênero: Masculino Relação com o autismo: Pai de autista BIOGRAFIA

Rodrigo é empresário e pai de dois filhos: uma crianca e um adolescente com transtorno do espectro autista.

\section{AUTISMO E TECNOLOGIA}

O filho de Rodrigo tem muito interesse em smartphones, tablets, computador $e$ televisão e disse que estes dispositivos podem ser muito bons quando utilizados com cautela e supervisionados. Rodrigo disse que seu filho se interessa muito pelas cores e sons e acredita que estas atribuições devem ser mais exploradas nos aplicativos para que prendam a atenção dos autistas. Além da personalizaçăo para diferentes niveis porque hoje seu filho é

adolescente e tem um desenvolvimento mais avançado do que crianças que estão tendo o primeiro contato, os aplicativos devem ser adaptáveis para todas as idades e desenvolvimento dos autistas.

Figura 8. Personas de mãe de autista e pai de autista obtidas por meio da netnografia.

A Figura 8 também ilustra a persona de um pai de autista, denominada Rodrigo Gonçalves. Esta persona foi criada com base na análise de duas fichas de extração. Rodrigo é empresário e pai de um adolescente autista. Seu filho tem muito interesse em tecnologia e Rodrigo acredita que a tecnologia pode ser uma aliada quando usada com cautela e sob supervisão. As cores e sons são recursos que despertam o interesse do filho de Rodrigo e por isso, Rodrigo acredita que estes recursos poderiam ser mais explorados nos aplicativos, assim como recursos de personalização.

A Figura 9 ilustra as personas de crianças autistas obtidas. Para gerar a persona da autista do sexo feminino (Figura 9) foi analisada uma ficha de extração de autista do sexo feminino e todas as outras fichas de extração dos perfis de pessoas relacionadas ao autismo. Yasmin Rebouças é uma criança diagnosticada com autismo Nível 2 (médio), que exige apoio substancial para suas atividades diárias. Por isso, Yasmin tem o acompanhamento de uma psicopedagoga e uma cuidadora. Sua mãe decidiu cursar Pedagogia para apoiar o desenvolvimento de Yasmin e vem incentivando a inclusão de 
tecnologia em sua rotina, especialmente jogos educativos. Yasmin gosta da variedade de cores e recursos audiovisuais dos aplicativos que utiliza.

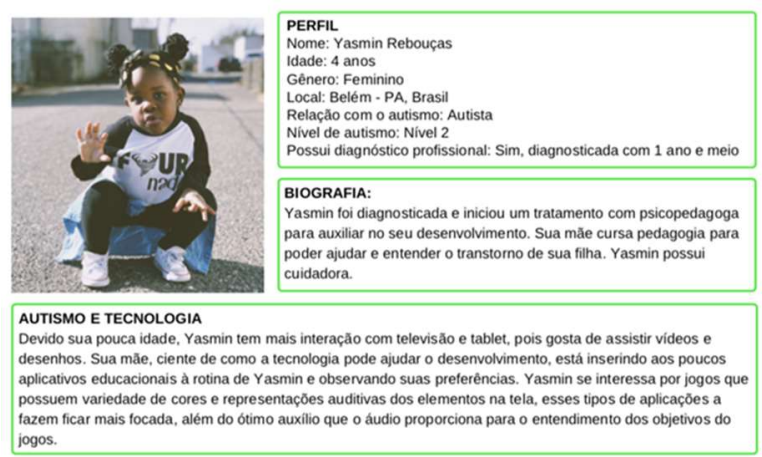

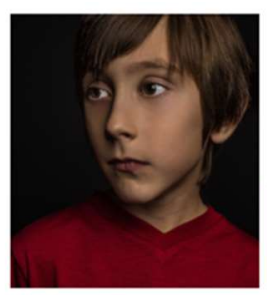

PERFIL
Nome: Davi Ribeiro Nome: Davi Ribe
Idade: 8 anos Lênero: Masculino
Local: Porto Alegre - RS, Brasil Relaçao com o autismo: Autista Nivel de autismo: Nivel
Possui diagnóstico profission Estico profissional: Sim, diagnosticado aos 2 anos BIOGRAFIA:

Davi faz acompanhamento com terapeuta, aulas de computacio - fisioterapia para desenvolver suas habilidades motors tem uma irmã e uma cuidadora desde quando foi diagnosticado.

AUTISMO E TECNOLOGIA
Davi sempre se interessou por tecnologia e seus pais o colocaram em aulas de computação pois Davi sempre se interessou por tecnologia e seus pais o colocaram em aulas de computaçáo pois
acreditam que a interaçăo pode ajudar muito o desenvolvimento de crianças autistas. Davi utiliza o Youtube para assistir videos e smartphones $\mathrm{e}$ tablets para aprendizado com jogos educativos aces para autismo. Davi precisa de aplicativos e jogos educacionais que 0 acompanhem conforme 0 desenvolvimento de sua altabetização para que não fiquem ultrapassados e não o agreguem mais aprendizado.

Figura 9. Personas de autistas obtidas por meio da netnografia.

Por sua vez, a persona do autista do sexo masculinho foi obtida por meio da análise de uma ficha de extração de um autista e todas as outras fichas de pessoas relacionadas ao autismo. Davi Ribeiro tem 8 anos e foi diagnosticado com Nível 1 (Leve) de autismo aos 2 anos. Davi possui cuidadora e realiza acompanhamento com terapeuta. Davi participa de aulas de Computação e Fisioterapia. Por ter mais experiência com tecnologia, Davi precisa de aplicativos e jogos que acompanhem seu desenvolvimento, fornecendo recursos que agreguem ao seu aprendizado.

A netnografia possibilitou ainda, criar personas que apoiam os cuidados e desenvolvimento de pessoas autistas: cuidadora e profissional da área de Direito (Figura 10). A persona de cuidadora foi criada por meio da análise de duas fichas de extração.

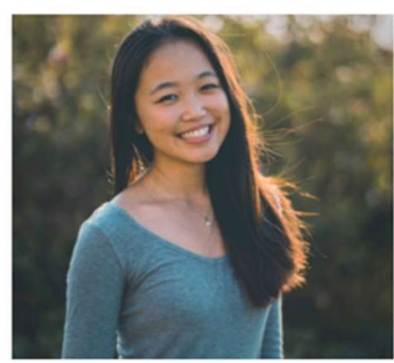

\section{PERFIL}

Nome: Adriana Rodrigues

Idade: 23 anos

Gênero: Feminino

Local: Fortaleza- CE, Brasil

Relação com o autismo: Cuidadora

\section{BIOGRAFIA:}

Adriana é cuidadora de uma

criança com autismo há 3 anos,

graduada em pedagogia.

\section{AUTISMO E TECNOLOGIA}

Acredita que a tecnologia pode ser uma ótima aliada ao aprendizado das crianças por poder representar diversas formas de interação (visual, auditiva, motora). Como os jogos e aplicativos podem conter instruções para auxiliar o manuseio, a criança pode tornar menos dependente de pessoas para as auxiliarem nas próximas vezes que forem utilizar os aplicativos.
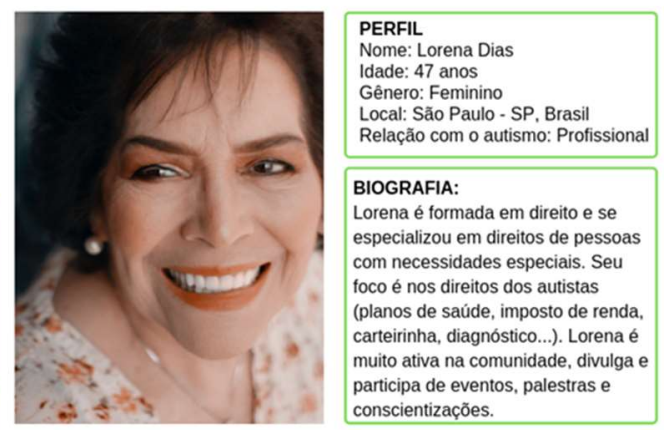

AUTISMO E TECNOLOGIA

Lorena diz que a tecnologia tem um potencial para ajudar o aprendizado de crianças autistas mas tem dificuldade de encontrar jogos educativos. Lorena ressaltou a importância de aplicativos que não precisem de conexão com ressaltou a importância de aplicativos que não precisem de conexão com
internet pois as crianças têm dificuldade de esperar e não entendem a falta de acesso quando estão sem conexăo.

Figura 10. Personas de cuidadora e profissional relacionadas ao TEA.

Adriana Rodrigues tem 23 anos, é graduada em Pedagogia e cuidadora de uma criança autista há 3 anos. Adriana acredita no potencial das tecnologias para o aprendizado de crianças autistas e considera importante que os aplicativos tenham instruções de manuseio para tornar as crianças mais independentes durante a interação.

Para criar a persona Lorena Dias foram analisadas quatro fichas de extração. Lorena tem 47 anos, é formada em Direito e especialista em direitos de pessoas com deficiência. Lorena é ativa na comunidade, divulga e participa de eventos sobre direitos 
dos autistas. Lorena acredita que a tecnologia pode auxiliar no aprendizado de crianças autistas, porém tem dificuldades de encontrar jogos educacionais adequados.

\subsection{Requisitos}

Para elicitar os requisitos, foi utilizado o campo "autismo e tecnologia" das personas, pois este campo continha as necessidades, dificuldades, melhorias esperadas e preferências do uso de tecnologia pelos autistas. A Figura 11 exemplifica a identificação de dois requisitos a partir da persona de Yasmin Rebouças.

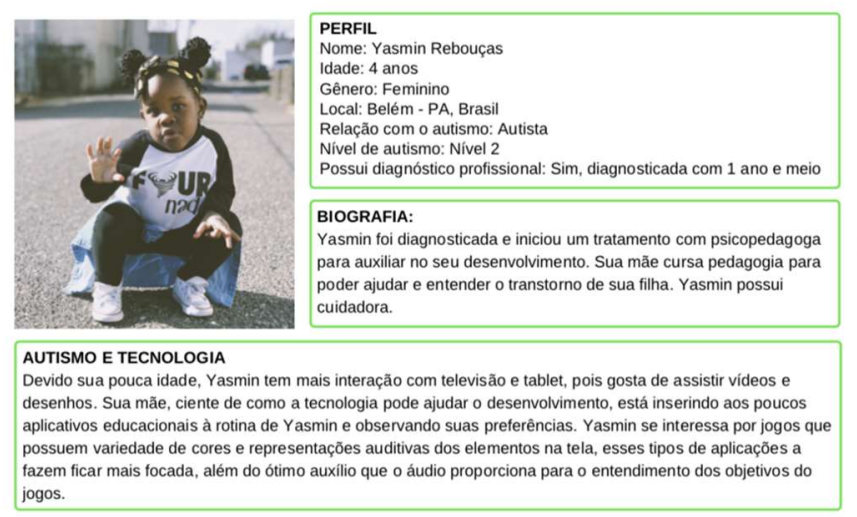

\begin{tabular}{|c|c|}
\hline Identificador & R02 \\
\hline Tipo de requisito & Funcional \\
\hline $\begin{array}{l}\text { Nome do } \\
\text { Requisito }\end{array}$ & Conter instruções de manuseio \\
\hline Descrição & $\begin{array}{l}\text { O sistema deve conter instruçöes de manuseio para } \\
\text { um melhor entendimento de suas funcionalidades e } \\
\text { facilitar o aprendizado dos autistas. }\end{array}$ \\
\hline Fonte & Adriana Rodrigues, Yasmin Rebouças \\
\hline Identificador & R03 \\
\hline Tipo de requisito & Funcional \\
\hline $\begin{array}{l}\text { Nome do } \\
\text { Requisito }\end{array}$ & Instruçōes por áudio \\
\hline Descrição & $\begin{array}{l}\text { O sistema deve possuir instruções por áudio para que } \\
\text { crianças que ainda năo saibam ler ou estão em fase } \\
\text { de aprendizado possam entender seu funcionamento. }\end{array}$ \\
\hline Fonte & Yasmin Rebouças \\
\hline
\end{tabular}

Figura 11. Exemplo de requisitos extraídos a partir das personas

A Tabela 3 resume os requisitos identificados a partir da análise das personas obtidas. Os requisitos descrevem funcionalidades e características que podem ser implementadas em qualquer sistema com foco em autismo, como jogos, aplicativos educacionais e podem ser incorporadas a sites para que sejam acessíveis para autistas.

Tabela 3. Requisitos identificados a partir das personas.

\begin{tabular}{|l|l|}
\hline \multicolumn{1}{|c|}{ Descrição } & Tipo de requisito \\
\hline $\begin{array}{l}\text { R01 - O sistema deve abordar diversas formas de interação para que o autista se } \\
\text { adapte melhor e desenvolva diferentes habilidades. }\end{array}$ & Não funcional \\
\hline $\begin{array}{l}\text { R02 - O sistema deve conter instruções de manuseio para um melhor entendimento } \\
\text { de suas funcionalidades e facilitar o aprendizado dos autistas. }\end{array}$ & Funcional \\
\hline $\begin{array}{l}\text { R03 - O sistema deve possuir instruções por áudio para que crianças que ainda não } \\
\text { saibam ler ou estão em fase de aprendizado possam entender seu funcionamento. }\end{array}$ & Funcional \\
\hline R04 - O sistema deve permitir a personalização de acordo com o nível de autismo. & Funcional \\
\hline $\begin{array}{l}\text { R05 - O sistema deve permitir que os pais, cuidadores e profissionais possam } \\
\text { configurar o sistema de acordo com o desenvolvimento do autista. }\end{array}$ & Funcional \\
\hline R06 - O sistema deve funcionar mesmo que não tenha acesso à internet. & Não funcional \\
\hline $\begin{array}{l}\text { R07 - O sistema deve possuir atividades que ajudem na alfabetização do autista, } \\
\text { semelhante às atividades realizadas em sala de aula para exercitar. }\end{array}$ & Funcional \\
\hline
\end{tabular}

Vale ressaltar que embora os requisitos tenham sido obtidos a partir de personas relacionadas ao autismo, alguns requisitos podem descrever necessidades comuns a outros perfis de usuários, como o requisito R06, que descreve uma característica de disponibilidade esperada em sistemas no geral. 
A Tabela 4 apresenta a rastreabilidade dos requisitos com as personas a partir das quais foram obtidos. Embora tenham sido obtidos de diferentes fontes, todos os requisitos se aplicam a tecnologias direcionadas para crianças autistas.

Tabela 4. Matriz de rastreabilidade da fonte dos requisitos.

\begin{tabular}{|l|c|c|c|c|c|c|c|}
\hline Fonte / Requisito & $\mathrm{R} 01$ & $\mathrm{R} 02$ & $\mathrm{R} 03$ & $\mathrm{R} 04$ & $\mathrm{R} 05$ & $\mathrm{R} 06$ & $\mathrm{R} 07$ \\
\hline Fabiana Freitas & & & & $\mathrm{X}$ & $\mathrm{X}$ & & $\mathrm{X}$ \\
\hline Rodrigo Gonçalves & $\mathrm{X}$ & & & $\mathrm{X}$ & $\mathrm{X}$ & & \\
\hline Yasmin Rebouças & $\mathrm{X}$ & $\mathrm{X}$ & $\mathrm{X}$ & & & & \\
\hline Davi Ribeiro & & & & $\mathrm{X}$ & $\mathrm{X}$ & & \\
\hline Adriana Rodrigues & $\mathrm{X}$ & $\mathrm{X}$ & & & & & \\
\hline Lorena Dias & & & & & & $\mathrm{X}$ & \\
\hline
\end{tabular}

\section{Avaliação das personas}

Com o intuito de avaliar a qualidade das personas criadas por meio da netnografia e viabilizar sua adoção em projetos de desenvolvimento de software, foram adotados dois métodos: questionário e grupo focal. As etapas seguidas para avaliação das personas serão descritas nesta seção.

\subsection{Questionário com o instrumento PPS}

Uma pesquisa por meio de questionário online foi realizada com o intuito de coletar a percepção de profissionais de desenvolvimento de software acerca das personas obtidas. Para garantia dos preceitos éticos em pesquisas de opinião, de acordo com as diretrizes fornecidas por Martins et al. (2021), na introdução do questionário, os pesquisadores apresentaram o Termo de Consentimento Livre e Esclarecido (TCLE) esclarecendo o objetivo da pesquisa, perfil esperado dos respondentes, participação voluntária, confidencialidade dos dados e uso dos dados somente para fins da pesquisa. Para responder ao questionário, era necessário que o respondente indicasse seu consentimento pós-informação.

A coleta de dados foi realizada com o uso do instrumento PPS (Salminen et al. 2020), com os seguintes fatores: completude (CO), disposição de uso (DU), clareza (CL) e empatia (EM). Estes fatores foram selecionados por considerarmos que estão relacionados à aceitação e intenção de adotar as personas no desenvolvimento de novos produtos. Os fatores são resumidamente descritos abaixo:

- Completude (CO) - define o quão bem a persona apresenta informações essenciais sobre os usuários que descreve;

- Disposição de uso (DU) - define o quão disposto o avaliador está para utilizar a persona;

- Clareza (CL) - define o quão claramente a informação da persona é apresentada;

- Empatia (EM) - define o quão bem o avaliador se familiariza com a persona.

A Tabela 5 apresenta as questões associadas aos fatores selecionados, conforme proposto por Salminen et al. (2020). Cada questão é respondida por meio de uma escala 
de concordância de cinco pontos variando de "concordo totalmente" a "discordo totalmente", considerando também a possibilidade de resposta neutra. Todas as questões deveriam ser respondidas a respeito de cada uma das seis personas. Neste questionário, não foi explorado se os respondentes possuíam experiência profissional ou alguma relação com o TEA, pois o foco foi selecionar pessoas com experiência no desenvolvimento de software.

O questionário foi divulgado no perfil do ProDTeA do Instagram por meio de directs para pessoas que tinham experiência em desenvolvimento de software e no sistema acadêmico da instituição pelas docentes envolvidas na pesquisa.

\section{Tabela 5. Questões associadas aos fatores selecionados para avaliação das} personas.

\begin{tabular}{|l|}
\hline \multicolumn{1}{|c|}{ Questão } \\
\hline $\begin{array}{l}\text { CO1 - O perfil da persona é detalhado o suficiente para tomar decisões sobre as personas que ele } \\
\text { descreve. }\end{array}$ \\
\hline CO2 - O perfil da persona parece completo. \\
\hline CO3 - O perfil da persona fornece informações suficientes para entender as pessoas que ela descreve. \\
\hline CO4 - No perfil da persona não faltam informações essenciais. \\
\hline DU1 - Eu usaria essa persona em pesquisas e práticas profissionais que envolvem pessoas com TEA. \\
\hline $\begin{array}{l}\text { DU2 - Posso imaginar maneiras de usar as informações da persona em pesquisas e práticas } \\
\text { profissionais que envolvem pessoas com TEA. }\end{array}$ \\
\hline DU3 - Essa persona melhoraria minha capacidade de tomar decisões sobre as pessoas que ela descreve. \\
\hline CL1 - As informações sobre a persona são bem apresentadas. \\
\hline CL2 - O texto no perfil da persona é claro o suficiente para ser lido. \\
\hline CL3 - As informações no perfil da persona são fáceis de entender. \\
\hline EM1 - Sinto que entendo essa persona. \\
\hline EM2 - Sinto fortes laços com essa persona. \\
\hline EM3 - Eu posso imaginar um dia na vida dessa persona. \\
\hline
\end{tabular}

O questionário permaneceu aberto para o recebimento de respostas durante 15 dias. Após este período, foram obtidas 33 respostas válidas. As respostas coletadas por meio do questionário podem ser acessadas em $<$ https://bitlybr.com/8118Q3t $>$.

A Figura 12 apresenta a caracterização dos respondentes do questionário. Dos respondentes, 17 possuem entre um e três anos de experiência em desenvolvimento de software, enquanto 10 possuem mais de três anos e seis respondentes possuem menos de um ano. Quanto ao papel desempenhado no desenvolvimento de software, destaca-se que 22 respondentes indicaram atuar como desenvolvedor, 14 indicaram atuar como projetista, outros 14 indicaram atuar como analista de sistema e 11 atuam como testador. Houve respostas para cientista de dados, analista de dados, arquiteto e analista de qualidade. Ressalta-se que cada respondente poderia indicar mais de um papel. 


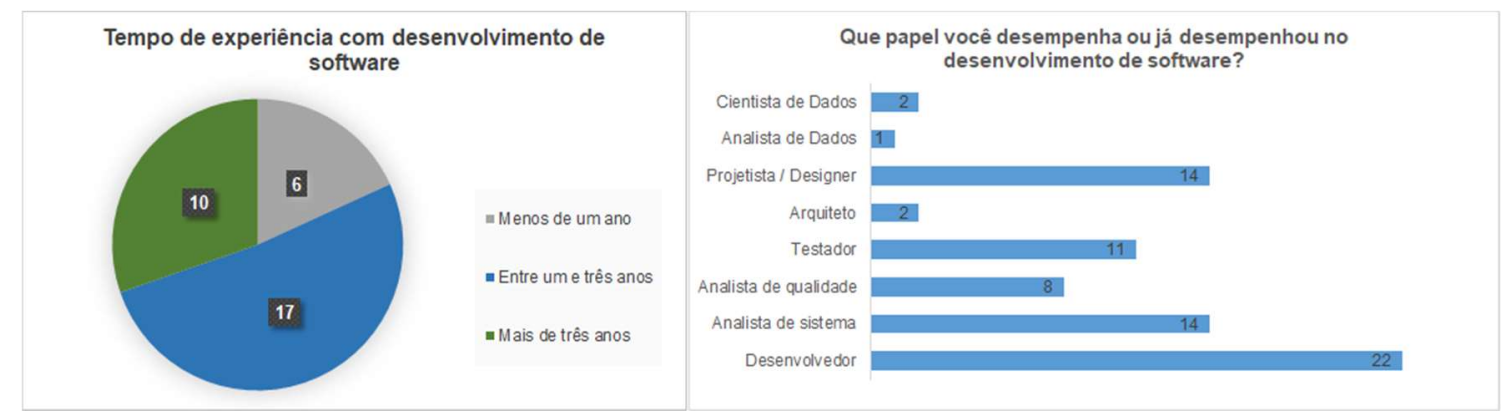

Figura 12. Caracterização dos respondentes do questionário.

Todas as personas foram avaliadas por todos os 33 respondentes. Os resultados obtidos para cada persona serão discutidos a seguir. Foram criados gráficos que resumem os resultados para cada fator do instrumento PPS considerado no questionário.

A Figura 13 apresenta os resultados da avaliação da persona Fabiana Freitas, que representa uma mãe de crianças autistas. A maioria dos respondentes concordou com todas as afirmativas que avaliam a completude, clareza e disposição de uso. Contudo, em relação à empatia, mais da metade dos respondentes foi indiferente sobre a afirmativa "sinto fortes laços com essa persona". Por outro lado, a maioria concorda (totalmente ou não) que poderia imaginar um dia na vida da persona e que sentia que a entendia.

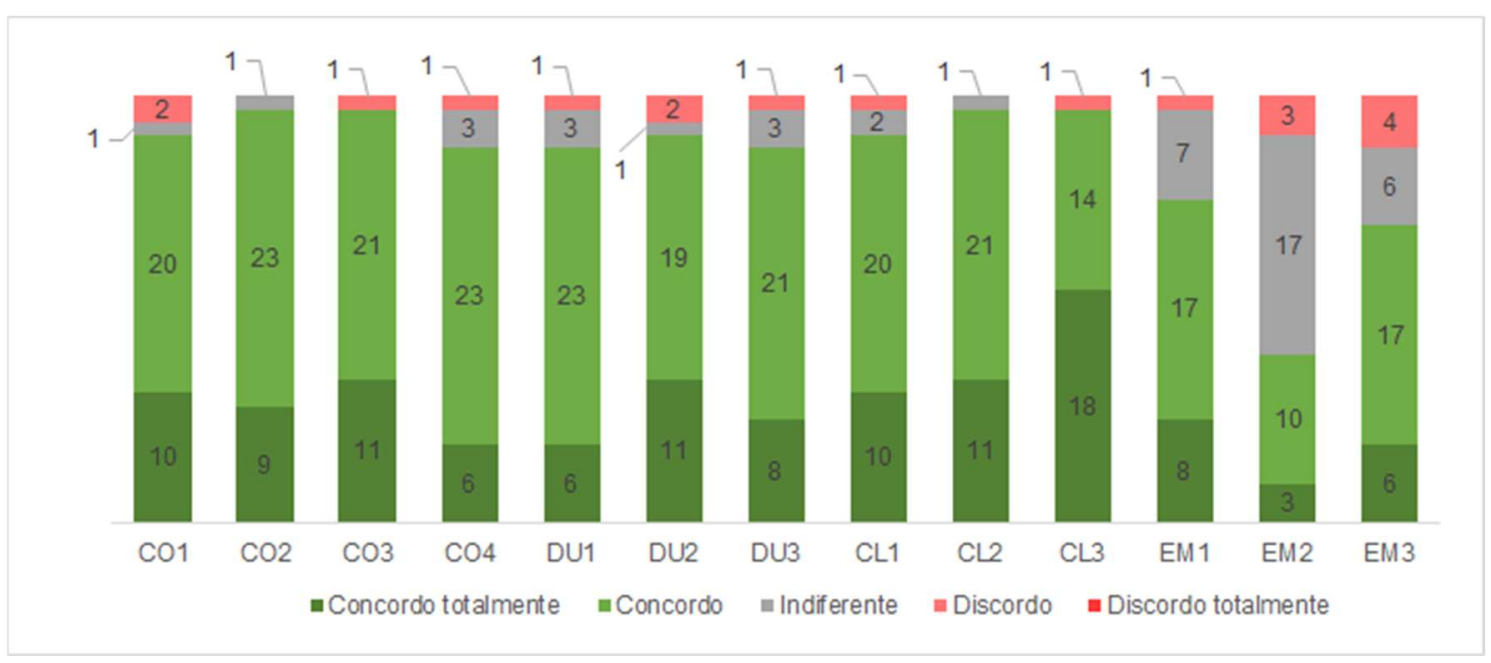

Figura 13. Resultados da avaliação da persona Fabiana Freitas (mãe).

Os resultados da avaliação da persona Rodrigo Gonçalves, que representa um pai de crianças autistas, são resumidos na Figura 14. Em relação aos fatores de completude, clareza e disposição de uso, a maioria dos respondentes concordou com as afirmativas que os avaliam. Observou-se que uma maior quantidade de respondentes indicou neutralidade quanto às afirmativas sobre empatia. 


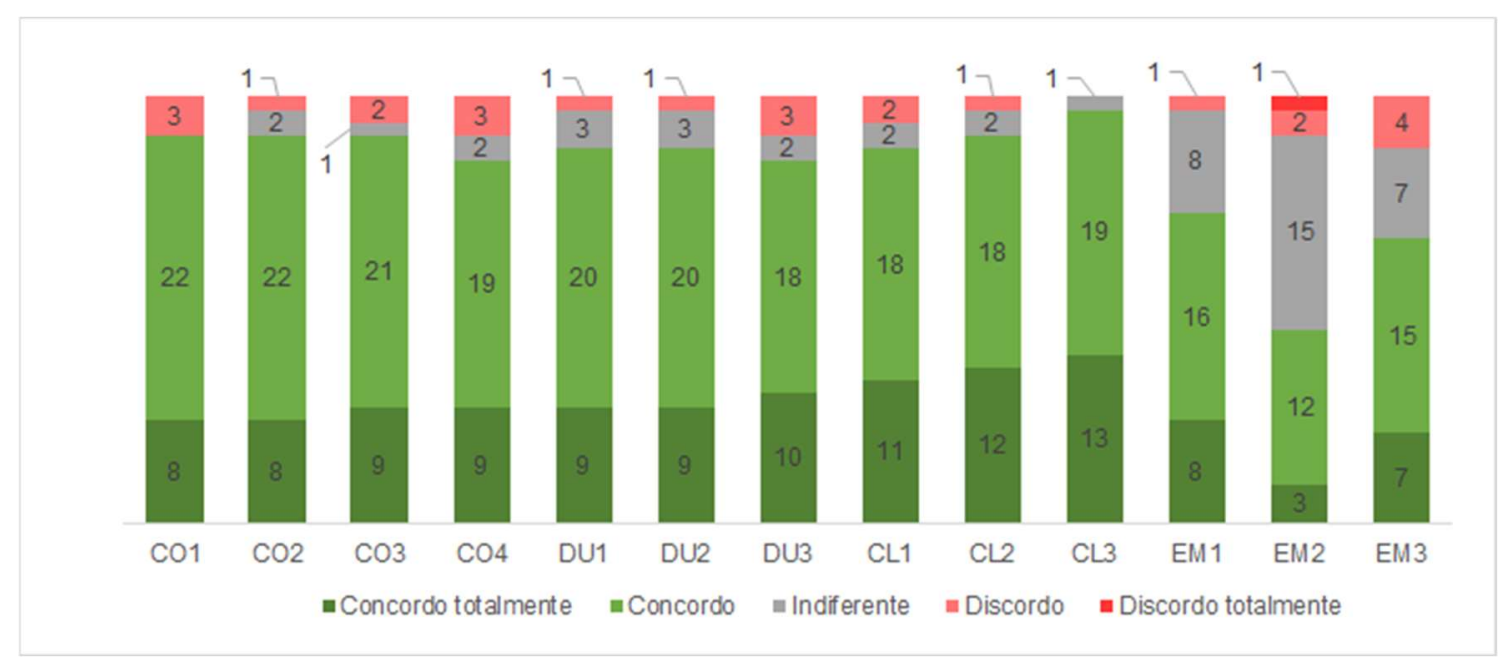

Figura 14. Resultados da avaliação da persona Rodrigo Gonçalves (pai).

A Figura 15 resume os resultados da avaliação da persona Yasmin Rebouças, uma criança autista. A maioria dos respondentes concordou com as afirmativas que avaliam a completude, clareza e disposição de uso. Nenhum respondente discorda que a persona fornece informações suficientes (completude), que as informações são fáceis de entender (clareza) e que é possível imaginar formas de usar a persona em pesquisas ou práticas profissionais que envolvem o desenvolvimento de software para pessoas autistas (disposição de uso). Em relação à empatia, a maioria dos respondentes nem concorda, nem discorda que sente fortes laços com a persona.

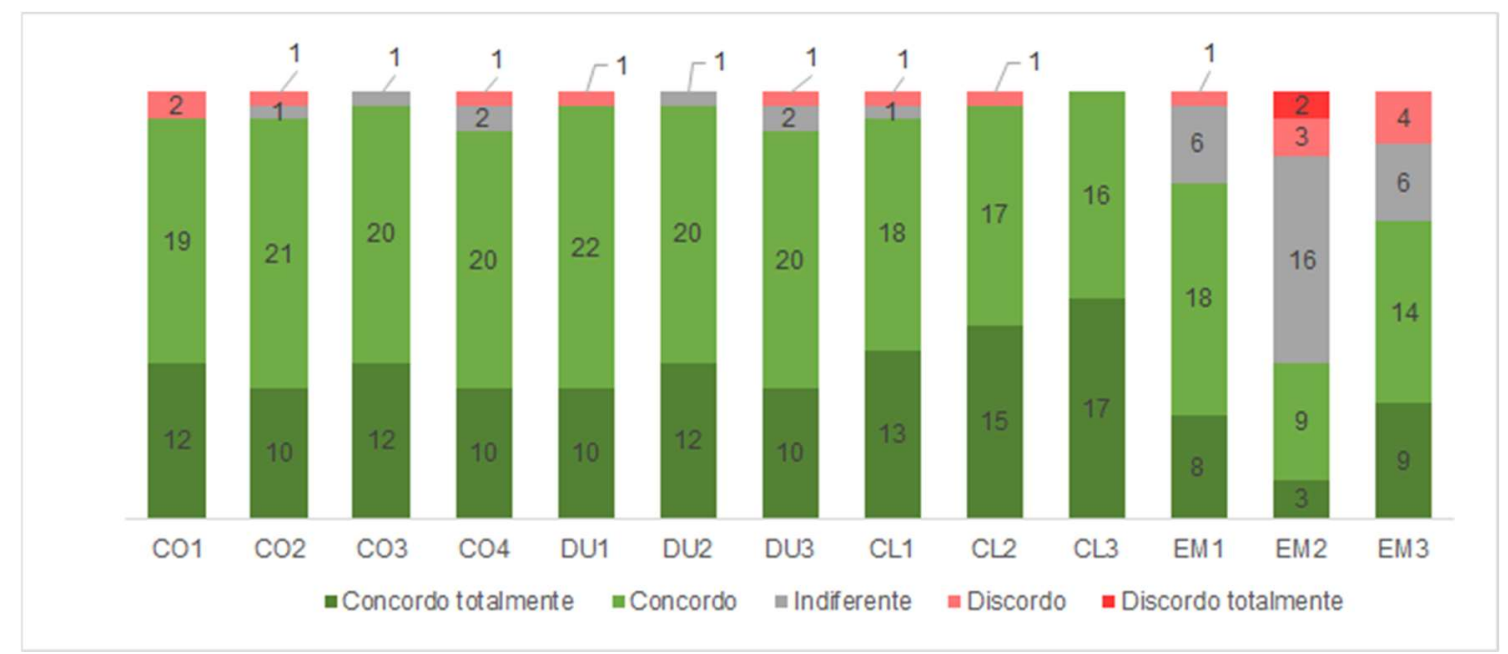

Figura 15. Resultados da avaliação da persona Yasmin Rebouças (criança autista).

Na Figura 16 são apresentados os resultados da avaliação da persona Davi Ribeiro, que também representa uma criança autista. 


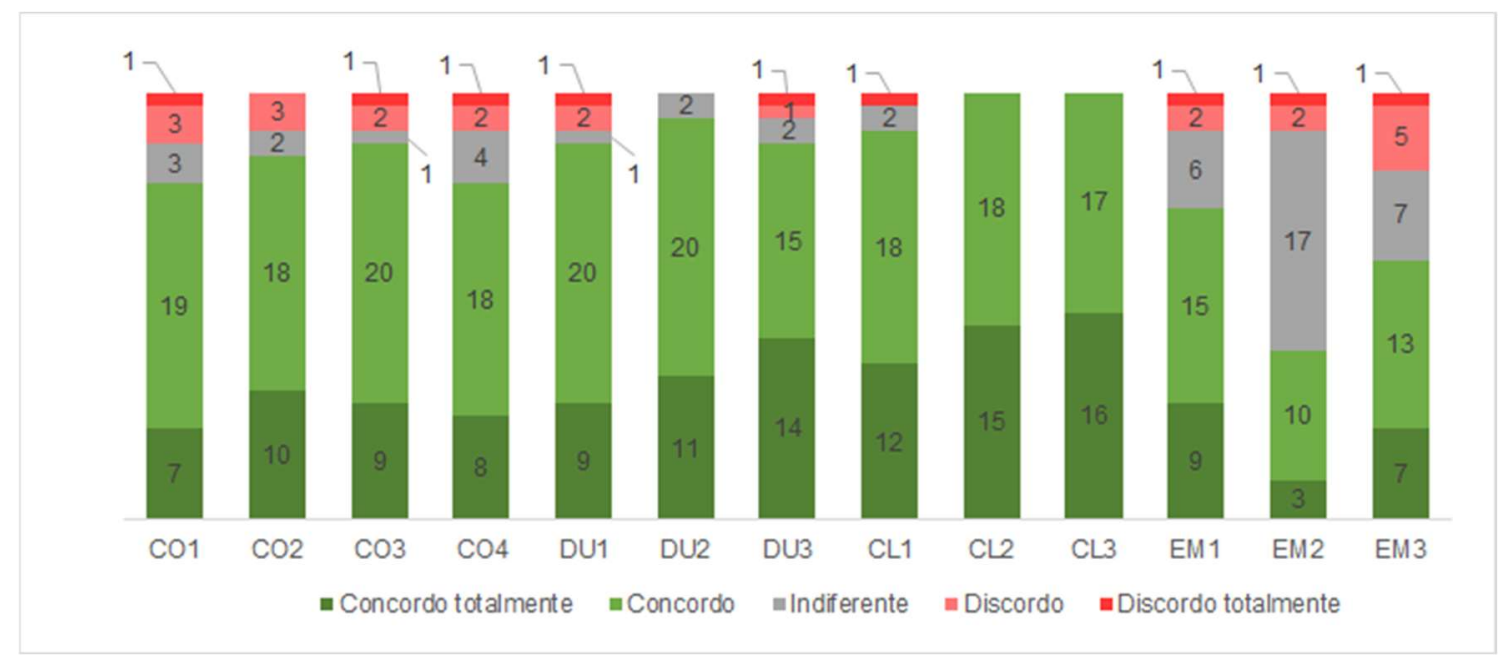

Figura 16. Resultados da avaliação da persona Davi Ribeiro (criança autista).

A maioria dos respondentes concorda com as afirmativas que avaliam a completude, clareza e disposição de uso. Porém, três respondentes ou mais discordam com as afirmativas sobre a completude. Nenhum respondente discorda que o conteúdo da persona é fácil de entender e claro o suficiente para ser lido. Sobre a empatia, pelo menos três respondentes discordam de todas as afirmativas.

Os resultados da avaliação da persona da cuidadora Adriana Rodrigues são apresentados na Figura 17. Um maior número de respondentes discorda das afirmativas sobre completude, disposição de uso e empatia, em comparação com os resultados obtidos sobre as personas anteriores (mãe, pai e crianças autistas). Isto pode indicar a necessidade de melhoria no conteúdo da persona Adriana para torná-la mais completa e adequada para uso por profissionais de desenvolvimento de software.

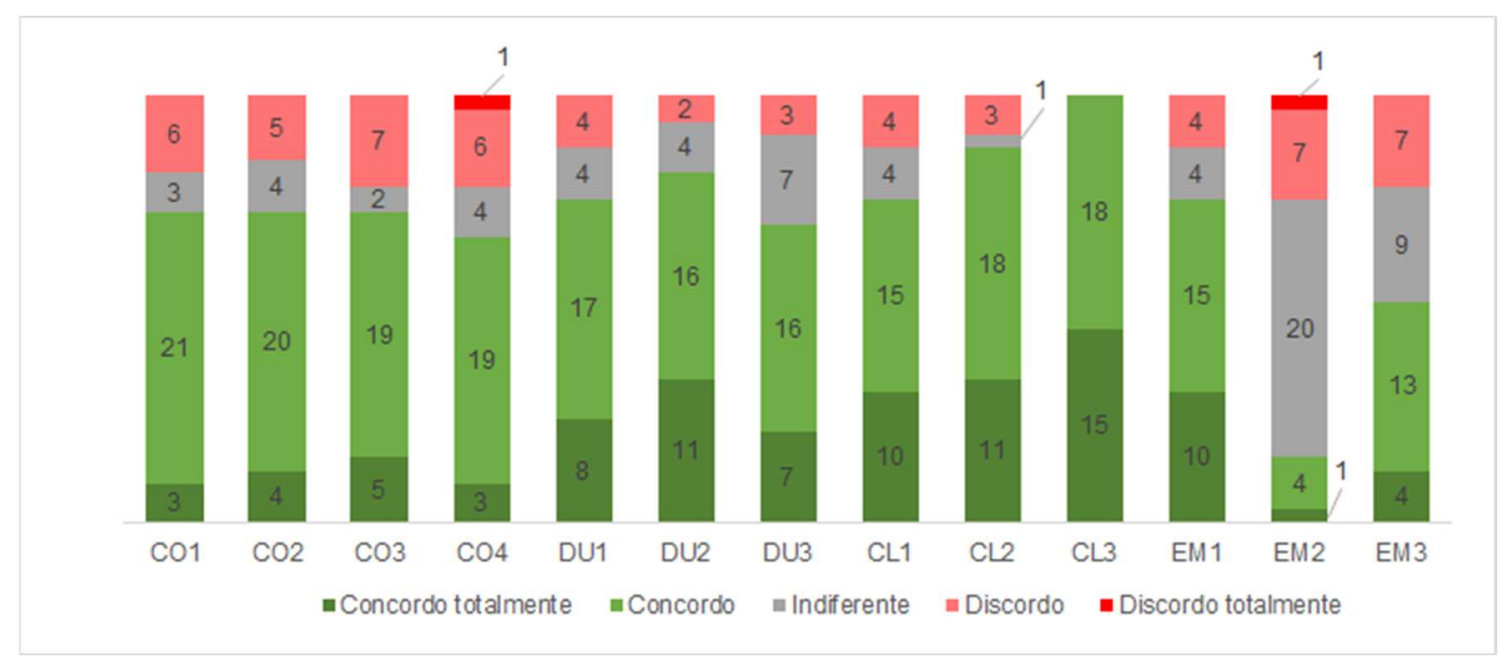

Figura 17. Resultados da avaliação da persona Adriana Rodrigues (cuidadora).

Por fim, a Figura 18 apresenta os resultados da avaliação da persona Lorena Dias, uma profissional da área de Direito de pessoas autistas. Cinco respondentes discordam que a persona possui informações suficientes e que a persona parece completa. Ainda assim, a maioria dos respondentes concorda com todas as afirmativas a respeito da completude, clareza e disposição de uso. Em relação à empatia, a maioria dos 
respondentes foi indiferente quanto a sentir fortes laços com a persona, mas concorda que pode imaginar um dia na vida da persona e entender a persona.

Salminen et al. (2020), autores do instrumento PPS, sugerem a obtenção de uma nota para cada fator avaliado, assim como uma nota geral para as personas avaliadas, por meio da atribuição de valores para a escala de concordância e posterior cálculo da média das respostas. Com isso, foram atribuídos os seguintes valores para a escala de concordância utilizada na avaliação: discordo totalmente $=1$, discordo $=2$, indiferente $=$ 3 , concordo $=4$ e concordo totalmente $=5$. Desta forma, foi possível calcular a nota de cada persona em relação à completude $(C O)$, clareza $(C L)$, disposição de uso (DU) e empatia (EM) por meio da média das respostas obtidas dos 33 respondentes (Tabela 6).

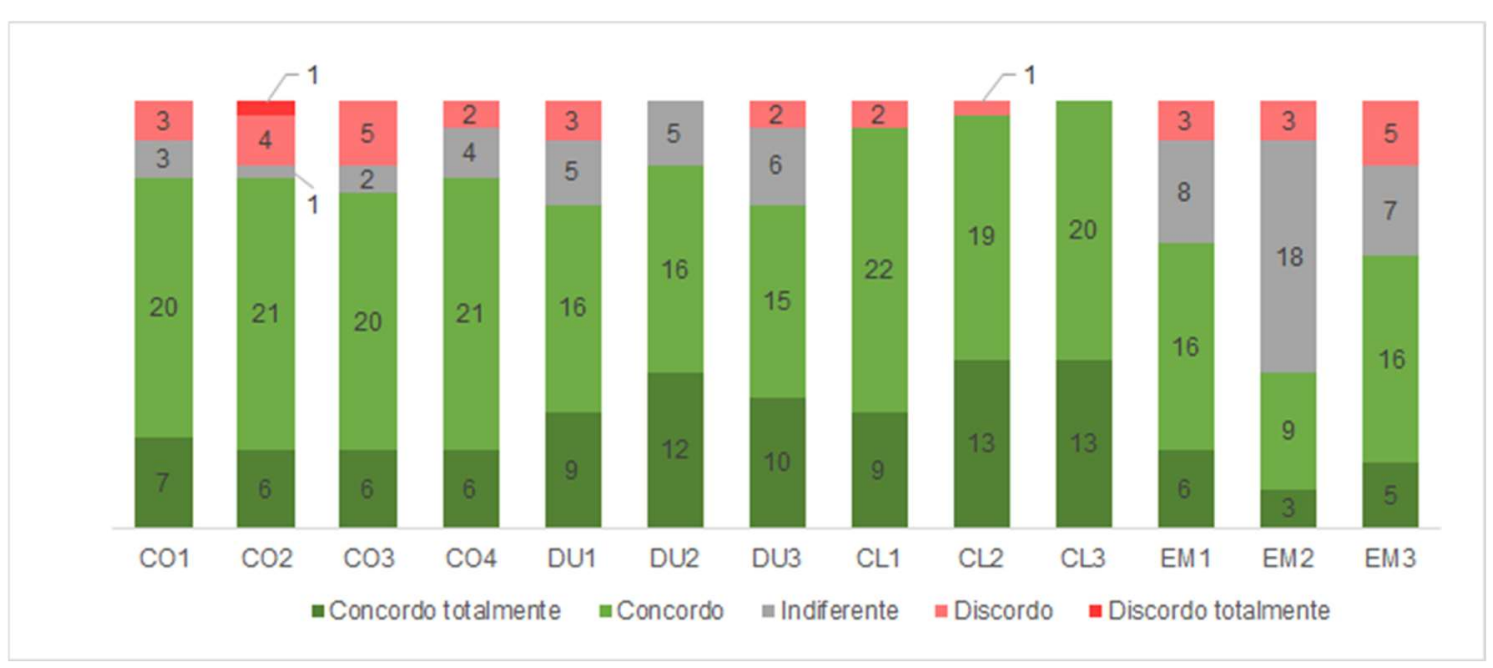

Figura 18. Resultados da avaliação da persona Lorena Dias (profissional).

Para o cálculo da nota de qualidade geral, foram seguidas as recomendações de Salminen et al. (2020) para medir a qualidade das personas. Assim, os valores relacionados à escala de concordância foram divididos em faixas, da seguinte maneira: qualidade baixa $(1<=$ qualidade $<=2)$; qualidade média $(2<$ qualidade $<4)$; qualidade alta $(4<=$ qualidade $<=5)$. A Tabela 6 apresenta o resultado dos indicadores calculados sobre a qualidade das personas.

Tabela 6. Resultado dos indicadores de qualidade das personas.

\begin{tabular}{|c|c|c|c|c|c|c|}
\hline PERSONA & CO & DU & CL & EM & $\begin{array}{c}\text { Nota da } \\
\text { Qualidade Geral }\end{array}$ & Classificação Geral \\
\hline Fabiana Freitas & 4,31 & 4,10 & 4,34 & 3,71 & 4,11 & Qualidade alta \\
\hline Rodrigo Gonçalves & 4,01 & 4,02 & 4,31 & 3,72 & 4,01 & Qualidade alta \\
\hline Yasmin Rebouças & 4,21 & 4,31 & 4,30 & 3,71 & 4,13 & Qualidade alta \\
\hline Davi Ribeiro & 4,11 & 4,10 & 4,21 & 3,70 & 4,03 & Qualidade alta \\
\hline Adriana Rodrigues & 3,61 & 3,90 & 4,01 & 3,41 & 3,73 & Qualidade média \\
\hline Lorena Dias & 3.90 & 4.01 & 4.30 & 3.60 & 3.95 & Qualidade média \\
\hline
\end{tabular}


As personas Fabiana Freitas, Rodrigo Gonçalves, Yasmin Rebouças e Davi Ribeiro obtiveram notas iguais ou maiores que 4.0, sendo classificadas como personas de qualidade alta. As personas Adriana Rodrigues e Lorena Dias obtiveram notas ligeiramente menores que 4.0, sendo classificadas como personas de qualidade média, segundo os critérios de qualidade selecionados nesta pesquisa.

Analisando as notas obtidas para as personas Adriana Rodrigues e Lorena Dias, nota-se que valores menores foram obtidos para a completude (CO) e empatia (EM). Tal fato pode indicar que os respondentes consideram que faltam informações nas personas e esta ausência de informação pode ter impactado negativamente na criação de empatia, que permitiria que os respondentes compreendessem as personas e se identificassem com sua realidade.

Para investigar o que pode ter ocasionado os resultados observados por meio do questionário, assim como explorar o potencial das personas para uso em projetos de desenvolvimento de software direcionados a usuários autistas, decidiu-se conduzir um grupo focal com integrantes do projeto ProDTeA.

\subsection{Grupo focal com integrantes do projeto ProDTeA}

O grupo focal objetivou promover uma discussão sobre aspectos positivos e negativos da utilidade das personas para a concepção de produtos direcionados a pessoas autistas. Quatro integrantes do projeto ProDTeA que não estavam envolvidos na condução da netnografia foram convidados a participar do grupo focal. Visando garantir os preceitos éticos da pesquisa (Martins et al. 2021), ao realizar o convite, explicou-se aos participantes que a participação no grupo focal possuía caráter voluntário, que os participantes não seriam identificados durante a análise dos dados e que os dados seriam utilizados somente para fins de pesquisa.

A primeira e a terceira autora do artigo foram as mediadoras do grupo focal. Os participantes possuíam conhecimentos com pesquisas direcionadas ao autismo, o intuito foi selecionar pessoas com experiência em estudos sobre TEA para coletar visões sobre pontos positivos e pontos negativos do uso dessas personas para o desenvolvimento de software.

Para incentivar os participantes a exporem seus pontos de vista negativos, foi utilizada uma dinâmica de Lovers X Haters (Colucci, 2008; De França et al. 2015), na qual cada participante possuía um papel pré-definido durante a discussão. Nesta dinâmica, a discussão deve ser conduzida sobre tópicos previamente definidos.

Para orientar a discussão no grupo focal, com a dinâmica Lovers X Haters, foi elaborado um quadro no Jamboard com os tópicos a serem discutidos (Figura 19). No início da sessão, o papel de cada participante (lover ou hater) foi definido de forma aleatória pelas mediadoras do grupo focal, da seguinte maneira: persona Adriana Rodrigues (lovers: P1 e P2; haters: P3 e P4), persona Fabiana Freitas (lovers: P3 e P4; haters: P1 e P2), persona Yasmin Rebouças (lovers: P1 e P3; haters: P2 e P4), persona Davi Ribeiro (lovers: P2 e P4; haters: P1 e P3), persona Rodrigo Gonçalves (lovers: P1 e P2; haters: P3 e P4), persona Lorena Dias (lovers: P3 e P4; haters: P1 e P2). 


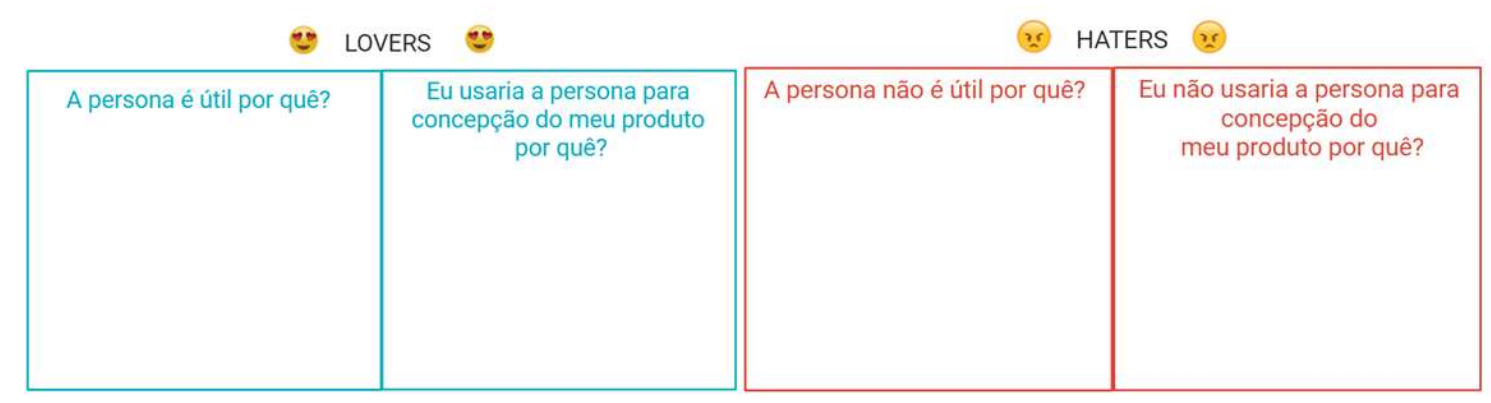

Figura 19. Quadro criado para orientar a discussão no grupo focal.

Foram conduzidas duas sessões do grupo focal, com intervalo de uma semana para a realização da segunda sessão. Na primeira sessão, foram avaliadas as personas Adriana Rodrigues, Fabiana Freitas e Yasmin Rebouças. Na segunda sessão, foram avaliadas as personas Davi Ribeiro, Rodrigo Gonçalves e Lorena Dias. Cada sessão teve duração de 1 hora. Os participantes tiveram 30 minutos para elaborar seus argumentos sobre cada tópico da discussão. Os argumentos deveriam ser registrados em post-its no quadro. Durante a discussão, cada participante explicava seus argumentos.

A Tabela 7 resume os aspectos positivos relatados sobre as personas avaliadas. De forma geral, os aspectos positivos sobre a utilidade das personas estão relacionados ao seu conhecimento sobre autismo e sua experiência com pessoas autistas. Em relação ao potencial de uso das personas na concepção de novos produtos, destacam-se comentários relacionados ao uso de tecnologia pelas personas e recursos sugeridos ou considerados como relevantes, que podem apoiar no desenvolvimento de tecnologias adequadas.

A Tabela 8 resume os comentários dos participantes sobre os aspectos negativos das personas avaliadas. Tais comentários foram fornecidos pelos participantes exercendo o papel de hater durante o grupo focal. Em alguns momentos da discussão, os participantes relataram dificuldades em encontrar argumentos negativos sobre as personas.

Os aspectos que afetaram negativamente a utilidade das personas, do ponto de vista dos participantes, foram a falta de informação sobre características das crianças autistas, como presença de comunicação verbal ou não verbal, assim como a ausência de informações sobre de que forma a tecnologia pode ser útil e apoiar no desenvolvimento de pessoas autistas. Comentários similares foram fornecidos sobre fatores que levariam a não adoção das personas: falta de informações sobre como a tecnologia pode apoiar na educação, características esperadas de jogos educacionais e características de tecnologias que podem promover o engajamento dos usuários.

Diante dos resultados obtidos no questionário e no grupo focal, observou-se que mesmo as personas que obtiveram qualidade média, possuem características que as tornam úteis para a concepção de novos produtos. Os pontos negativos das personas estão relacionados à necessidade de enriquecimento do seu conteúdo, como a formação da cuidadora, os pontos para os quais a tecnologia pode auxiliar no aprendizado da criança, o nível de comunicação da criança e contribuições da persona da área de Direito a respeito dos direitos de autistas e a tecnologia. 
Tabela 7. Aspectos positivos sobre as personas avaliadas.

\begin{tabular}{|c|c|c|}
\hline Persona & A persona é útil por quê? & $\begin{array}{l}\text { Eu usaria a persona para concepção do meu } \\
\text { produto por quê? }\end{array}$ \\
\hline $\begin{array}{l}\text { Fabiana } \\
\text { Freitas }\end{array}$ & $\begin{array}{l}\text { “É uma persona com bastante experiência } \\
\text { sobre crianças com TEA." - P3 } \\
\text { "Ela demonstra entender a importância do } \\
\text { uso equilibrado da tecnologia para crianças } \\
\text { com TEA." - P4 }\end{array}$ & $\begin{array}{l}\text { "Por ter contato direto com duas crianças com } \\
\text { autismo, pode ter experiência sobre o assunto." - } \\
\text { P4 } \\
\text { "O fato de ela já utilizar alguns serviços de } \\
\text { tecnologia e estar familiarizada com eles, pode ser } \\
\text { muito útil para validar a futura aplicação." - P4 }\end{array}$ \\
\hline $\begin{array}{l}\text { Rodrigo } \\
\text { Gonçalves }\end{array}$ & $\begin{array}{l}\text { "É o relato de uma experiência vivenciada } \\
\text { sobre o beneficio do uso da tecnologia na } \\
\text { vida da criança." - P1 } \\
\text { "Ele incentiva a importancia da tecnologia } \\
\text { para seu filho e fala que aplicativos devem } \\
\text { ser adaptados para todas as idades." - } P 2\end{array}$ & $\begin{array}{l}\text { "Fica evidente quais aparelhos são utilizados, bem } \\
\text { como os elementos que influenciam para essa boa } \\
\text { experiência, como cores e sons." - P1 } \\
\text { "Mostra a importância da tecnologia e de seu uso } \\
\text { com acompanhamento." - P2 }\end{array}$ \\
\hline $\begin{array}{l}\text { Yasmin } \\
\text { Rebouças }\end{array}$ & $\begin{array}{l}\text { "Descreve como a tecnologia interfere na } \\
\text { vida da criança e os pontos que impactam, } \\
\text { como o uso de cores." - P1 } \\
\text { "É uma criança com TEA que teve o } \\
\text { diagnóstico cedo e portanto, pode revelar os } \\
\text { beneficios do acompanhamento médico } \\
\text { precoce." - P3 }\end{array}$ & $\begin{array}{l}\text { "É uma criança com TEA que se revela animada } \\
\text { com novas tecnologias." - P3 } \\
\text { "São destacados tópicos essenciais de impacto no } \\
\text { uso dos aplicativos que podem ser levados em } \\
\text { consideração no desenvolvimento da aplicação, } \\
\text { como cores, áudio, elementos visuais." - P1 }\end{array}$ \\
\hline $\begin{array}{l}\text { Davi } \\
\text { Ribeiro }\end{array}$ & $\begin{array}{l}\text { “A idade é adequada e a criança já possui } \\
\text { conhecimento em Computação, cuidador, } \\
\text { terapeuta e diagnóstico médico." - P4 } \\
\text { "Ele já tem um conhecimento e um grande } \\
\text { interesse pela tecnologia e é acompanhado } \\
\text { desde seu diagnóstico com terapeuta e } \\
\text { cuidador.”- P2 }\end{array}$ & $\begin{array}{l}\text { "Os conhecimentos em computação que a criança } \\
\text { possui podem ser muito úteis na validação da } \\
\text { aplicação." - P4 } \\
\text { "Pelo fato de já utilizar jogos e aplicativos } \\
\text { educacionais de acordo com seu } \\
\text { desenvolvimento." - P2 }\end{array}$ \\
\hline $\begin{array}{l}\text { Adriana } \\
\text { Rodrigues }\end{array}$ & $\begin{array}{l}\text { "Pelo fato de descrever como a tecnologia } \\
\text { pode ser útil na vida da criança, } \\
\text { principalmente em relação ao aprendizado. } \\
\text { Além disso, cita um ponto importante que é } \\
\text { desenvolver a independência." - P1 } \\
\text { "Fala que a tecnologia é de grande } \\
\text { importância no aprendizado e na } \\
\text { independência das crianças." - } P 2\end{array}$ & $\begin{array}{l}\text { "Além de fornecer um feedback positivo sobre o } \\
\text { uso da tecnologia com crianças autistas, também } \\
\text { destaca pontos que podem ser levados em } \\
\text { consideração na hora do desenvolvimento, como } \\
\text { instruções de uso e a parte visual." - P1 } \\
\text { "Cita a importância da independência da criança } \\
\text { no manuseio de jogos e aplicações." - P2 }\end{array}$ \\
\hline $\begin{array}{l}\text { Lorena } \\
\text { Dias }\end{array}$ & "Conhece os direitos dos autistas." - P3 & $\begin{array}{l}\text { "O conhecimento jurídico da persona é de grande } \\
\text { valia para os quesitos técnicos da aplicação.”- } P 3 \\
\text { "Ela tem grande participação na comunidade de } \\
\text { pessoas que lutam pelos direitos dos autistas, } \\
\text { portanto conhece as dificuldades que existem para } \\
\text { eles na sociedade." - P4 }\end{array}$ \\
\hline
\end{tabular}

Todavia, essas informações são relevantes para as personas, mas não as tornam inadequadas para o uso. Desta forma, considera-se que as personas podem ser utilizadas e o seu conteúdo considerado para a concepção de novos produtos. Os participantes do grupo focal relataram ao final da discussão que todas as personas são essenciais para o 
desenvolvimento da pesquisa, visto que apresentam visões diferenciadas e informações relevantes.

Tabela 8. Aspectos negativos sobre as personas avaliadas.

\begin{tabular}{|c|c|c|}
\hline Persona & A persona não é útil por quê? & $\begin{array}{l}\text { Eu não usaria a persona para concepção do } \\
\text { meu produto por quê? }\end{array}$ \\
\hline $\begin{array}{l}\text { Fabiana } \\
\text { Freitas }\end{array}$ & $\begin{array}{l}\text { "Apesar de relatar que a tecnologia pode } \\
\text { ser útil para o aprendizado, não destaca } \\
\text { quais são os pontos que a tecnologia pode } \\
\text { auxiliar." - P1 }\end{array}$ & $\begin{array}{l}\text { "Não informa quais aspectos são essenciais para } \\
\text { promover o engajamento. Desse modo, o } \\
\text { desenvolvedor não saberia quais seriam os pontos } \\
\text { essenciais para existir na aplicação." - P1 }\end{array}$ \\
\hline $\begin{array}{l}\text { Rodrigo } \\
\text { Gonçalves }\end{array}$ & $\begin{array}{l}\text { "Não fica claro o nível de envolvimento do } \\
\text { pai com a tecnologia para pessoas com } \\
\text { TEA." - P3 }\end{array}$ & $\begin{array}{l}\text { "Ele acredita que cores e sons devem ser mais } \\
\text { exploradas nas aplicações para pessoas com TEA, } \\
\text { porém alguns sons podem causar incômodos aos } \\
\text { autistas e cores também devem ser usadas com } \\
\text { atenção na sua saturação e contraste com o } \\
\text { fundo." - P3 }\end{array}$ \\
\hline $\begin{array}{l}\text { Yasmin } \\
\text { Rebouças }\end{array}$ & $\begin{array}{l}\text { "Pela não definição da presença de fala e } \\
\text { comunicação por parte da persona." - P4 }\end{array}$ & $\begin{array}{l}\text { "Por não estar claro se ela é verbal ou não verbal, } \\
\text { a avaliação de uma futura aplicação poderia ser } \\
\text { comprometida." - P4 }\end{array}$ \\
\hline $\begin{array}{l}\text { Davi } \\
\text { Ribeiro }\end{array}$ & $\begin{array}{l}\text { "Não ficou claro qual é o nível de } \\
\text { comunicação que a criança tem." - P3 } \\
\text { "Não fala de que forma a tecnologia } \\
\text { interfere, nem as principais dificuldades da } \\
\text { criança que podem ser auxiliadas pela } \\
\text { tecnologia." - P1 }\end{array}$ & $\begin{array}{l}\text { "Não ficou claro em qual sentido do } \\
\text { desenvolvimento (fala, interação, alfabetização, } \\
\text { etc) a tecnologia vai ajudar." - Pl }\end{array}$ \\
\hline $\begin{array}{l}\text { Adriana } \\
\text { Rodrigues }\end{array}$ & $\begin{array}{l}\text { "Não fica claro se a persona tem } \\
\text { especialidade em autismo." - P4 }\end{array}$ & $\begin{array}{l}\text { "Talvez a experiência da cuidadora com } \\
\text { tecnologias não seja muito grande, o que pode } \\
\text { levar a um julgamento incompleto da aplicação." - } \\
\text { P4 }\end{array}$ \\
\hline $\begin{array}{l}\text { Lorena } \\
\text { Dias }\end{array}$ & $\begin{array}{l}\text { "Ela não tem experiência lidando } \\
\text { diretamente com o cotidiano de uma criança } \\
\text { autista e não fala com clareza a utilidade } \\
\text { que a tecnologia pode proporcionar." - P2 } \\
\text { "Possui conhecimento jurídico, porém não } \\
\text { faz nenhum comentário relacionando os } \\
\text { direitos e a tecnologia, que poderiam } \\
\text { auxiliar no desenvolvimento de novos } \\
\text { softwares." - P1 }\end{array}$ & $\begin{array}{l}\text { "Ela retrata a dificuldade de encontrar jogos } \\
\text { educacionais, mas existem alguns no mercado, } \\
\text { porém essa dificuldade deve se dar pela procura } \\
\text { de características específicas que não estão } \\
\text { especificadas no conteúdo da persona." - P1 } \\
\text { "Não deixa claro em como a tecnologia pode } \\
\text { ajudar na educação de uma criança autista." - P2 }\end{array}$ \\
\hline
\end{tabular}

\section{Ameaças à validade}

Nesta seção serão discutidas as ameaças à validade identificadas pelos pesquisadores e a estratégia adotada para minimizá-las durante a pesquisa.

Para reduzir o viés do pesquisador durante a condução da netnografia, foram definidos critérios para a seleção de perfis de interesse no Instagram, quantidade de postagens a serem analisadas e um formulário de extração de informações para a criação das personas. Todas as etapas da netnografia foram conduzidas por um pesquisador e validadas por uma segunda pesquisadora com experiência na criação de personas e pesquisas sobre autismo. A representatividade das personas é diretamente relacionada aos perfis analisados nas redes sociais. Considerando que a amostra de perfis analisados foi 
limitada (menor que 50), uma extensão da netnografia com um maior número de perfis ou ainda, em outras plataformas online e redes sociais, pode aumentar a representatividade das personas.

A etapa de avaliação das personas requer que os resultados sejam confiáveis para permitir a obtenção de uma conclusão correta sobre a qualidade das personas. Para garantir a confiabilidade das medidas de qualidade das personas, o instrumento PPS foi adotado por ser um instrumento cuja confiabilidade foi validada em estudos anteriores, segundo Salminen et al. (2020). Outro fator que pode influenciar o resultado é o tamanho e representatividade da amostra de avaliadores. Visando uma maior representatividade da amostra, profissionais da indústria de desenvolvimento de software foram convidados a avaliar as personas. Porém, estes profissionais não possuíam experiência com autismo. Para obter feedback de avaliadores com experiência com autismo, foram convidados a participar do grupo focal, estudantes do projeto ProDTeA com experiência na condução de pesquisas sobre autismo e tecnologia. Desta forma, foram obtidos pontos de vista de diferentes perfis de avaliadores com potencial para utilizar as personas avaliadas.

\section{Conclusões e Lições aprendidas}

Este artigo apresentou um relato de experiência da condução de netnografia no projeto ProDTeA, que visa desenvolver tecnologias acessíveis para pessoas com TEA. A netnografia possibilitou a geração de personas e requisitos para futuras aplicações. Visando avaliar a qualidade das personas obtidas antes de sua adoção em projetos de desenvolvimento de software, uma estratégia de avaliação foi definida. Um questionário online com base no instrumento PPS (Persona Perception Scale) foi aplicado com 33 profissionais da área de desenvolvimento de software e um grupo focal foi conduzido com quatro integrantes do projeto ProDTeA. Os resultados do questionário indicaram que quatro personas apresentam qualidade alta e duas personas apresentam qualidade média. A discussão no grupo focal indicou que mesmo as personas com qualidade média possuem características que as tornam úteis para a concepção de novos produtos, embora o seu conteúdo possa ser enriquecido.

Como lições aprendidas desta experiência, podemos destacar que:

1) A rede social Instagram é uma fonte rica de informações e dados para netnografia, pois seus usuários compartilham um grande volume de informações e o direct permite a interação entre o pesquisador e os participantes.

2) Algumas particularidades do Instagram dificultaram a condução da netnografia: (a) o algoritmo para geração do feed de publicações não é baseado em ordem cronológica e mostra primeiramente as publicações de perfis de interesse, o que limitava as visualizações das postagens do perfil do projeto; (b) o Instagram bloqueou o perfil do projeto algumas vezes por seguir perfis com a mesma temática, sendo necessário um tempo de espera para continuar a imersão; (3) o Instagram bloqueou o início de conversas pelo direct, atrasando o envio dos TCLES e dos questionários.

3) As postagens no Instagram possuem uma grande diversidade de conteúdo, porém por meio da observação, foram obtidas poucas informações sobre o uso de tecnologia por pessoas autistas. Talvez plataformas mais direcionadas a esta temática possibilitem resultados mais ricos e direcionados ao uso de tecnologia. 
Ainda assim, a netnografia possibilitou uma maior imersão da equipe em relação ao público-alvo, indicando que a netnografia é uma técnica com potencial para ser adotada em projetos com público-alvo pouco acessível ou disperso. Espera-se encorajar a condução de netnografia em outras plataformas online e redes sociais, com diferentes públicos, para geração de diferentes artefatos de software. Pretende-se adotar as personas e requisitos obtidos nesta pesquisa no desenvolvimento de um aplicativo educacional para crianças autistas. As personas e requisitos obtidos nesta pesquisa podem ser refinados por meio de nova coleta de dados por meio de outros métodos como entrevistas, questionários ou netnografia em outros contextos não explorados nesta pesquisa.

\section{Agradecimentos}

Os autores agradecem o apoio financeiro da Universidade Federal do Ceará (UFC) por meio da concessão de bolsas ao projeto ProDTeA nas modalidades PIBITI e PREX. A primeira autora agradece ao apoio financeiro da FUNCAP (processo BP4-017200228.01.00/20).

\section{Referências}

American Psychiatric Association (APA). (2014) Manual Diagnóstico Estatístico de Transtornos Mentais: DSM-5. Porto Alegre: Artmed. 2014. [GS Search]

Barbosa, S. D. J. (2010) Interação Humano-Computador. Rio de Janeiro: Elsevier, 2010. [GS Search]

Beykikhoshk, A., Arandjelović, O., Phung, D., Venkatesh, S., \& Caelli, T. (2015). Using Twitter to learn about the autism community. Social Network Analysis and Mining, 5(1), 1-17. doi: 10.1007/s13278-015-0261-5 [GS Search]

Branco, K. D. S. C., Oliveira, R. A., Silva, F. L. D., de H. Rabelo, J., \& Marques, A. B. (2020). Does this persona represent me? investigating an approach for automatic generation of personas based on questionnaires and clustering. In Proceedings of the 19th Brazilian Symposium on Human Factors in Computing Systems. 1-6. doi: 10.1145/3424953.3426648 [GS Search]

Boscarioli, C., Araujo, R., \& Maciel, R. (2017). I GranDSI-BR-Grand Research Challenges in Information Systems in Brazil 2016-2026. Special Committee on Information Systems (CE-SI). Brazilian Computer Society (SBC). I GranDSI-BR. [GS Search]

Brewer, J. (2000). Ethnography. McGraw-Hill Education (UK), 2000. [GS Search]

Colucci, E. (2008). "Focus Groups can be fun": the use of activity-oriented questions in Focus Group discussions. Qualitative Health Research, 17(10), 1422-1433. doi: $\underline{10.1177 / 1049732307308129}$ [GS Search]

Da Silva, R., Aguiar, L., dos Santos, R., \& Gengivir, E. (2016). Levantamento de Papéis e Atores em um Ecossistema de Software no Domínio Público. In Anais do I Workshop sobre Aspectos Sociais, Humanos e Econômicos de Software, 76-80. [GS Search]

De França, B., Ribeiro, T., Santos, P., \& Travassos, G. (2015). Using Focus Group in Software Engineering: lessons learned on characterizing software technologies in 
academia and industry. XVIII Ibero-American Conference on Software Engineering, Track: XVII Workshop on Experimental Software Engineering, 351-364. [GS Search]

de Oliveira Junior, G. F., Ferreira, B., \& Marques, A. B. (2020). USARP method: eliciting and describing USAbility Requirements with Personas and user stories. In Proc. of the 34th Brazilian Symposium on Software Engineering, 437-446. doi: 10.1145/3422392.3422435 [GS Search].

Ferreira, B., Barbosa, S., \& Conte, T. (2018). Creating Personas focused on Representing Potential Requirements to Support the Design of Applications. In Proc. of the 17th Brazilian Symposium on Human Factors in Computing Systems, 1-9. doi: $\underline{10.1145 / 3274192.3274207}$ [GS Search]

Fontão, A., Ekwoge, O., Santos, R., \& Dias-Neto, A. (2017). Facing up the primary emotions in Mobile Software Ecosystems from Developer Experience. In Anais do II Workshop sobre Aspectos Sociais, Humanos e Econômicos de Software, 5-11. doi: $\underline{10.1145 / 3098322.3098325}$ [GS Search]

Kozinets, R. V. (2014) Netnografia: Realizando pesquisa etnográfica online. Porto Alegre: Penso, 2014. [GS Search]

Marques, A., \& Aires, G. (2020). Uso da Netnografia para a Geração de Personas e Requisitos para Sistemas com foco em pessoas com Transtorno do Espectro Autista: Um Relato de Experiência. In Anais do V Workshop sobre Aspectos Sociais, Humanos e Econômicos de Software, 1-10. doi: 10.5753/washes.2020.11192 [GS Search]

Marins, M., Miletto, E. M. (2015) Uso das Redes e Aplicações Multiplataformas como Fonte de Empatia e Criatividade do Design Thinking na Disciplina de Empreendedorismo, no Ensino Superior. In Anais do Computer on the Beach, 394403. [GS Search]

Martins, V. F., Junqueira, M. A., \& de Araujo, R. M. (2021). Ética da Pesquisa em Sistemas de Informação: Por que e como submeter meu projeto ao Comitê de Ética? In Tópicos Especiais em Sistemas de Informação: Minicursos SBSI 2021. Sociedade Brasileira de Computação. doi: $\underline{10.5753 / \mathrm{sbc} .6453 .5}$ [GS Search]

Melo, A. \& Abelheira, R. (2015) Design Thinking \& Thinking Design. São Paulo, Novatec. [GS Search]

Nielsen, L., \& Storgaard Hansen, K. (2014). Personas is applicable: a study on the use of personas in Denmark. In Proceedings of the SIGCHI Conference on Human Factors in Computing Systems, 1665-1674. doi: 10.1145/2556288.2557080 [GS Search]

Pinheiro, E. G., Lopes, L. A., Conte, T. U., \& Zaina, L. A. M. (2018). The contribution of non-technical stakeholders on the specification of UX requirements: an experimental study using the proto-persona technique. In Proceedings of the XXXII Brazilian Symposium on Software Engineering, 92-101. doi: $\underline{10.1145 / 3266237.3266268}$ [GS Search]

Rodrigues, K., Salerno, L., Johnstone, L., Jesus, M., \& Silveira, M. (2018). A Saúde da Mulher e a Tecnologia: Uma Análise Heurística e Netnográfica do Aplicativo Clue. In Anais Estendidos do XVII Simpósio Brasileiro sobre Fatores Humanos em Sistemas Computacionais, 1-10. doi: 10.5753/ihc.2018.4202. [GS Search] 
Rotman, D., Preece, J., He, Y., Druin, A. (2012) Extreme Ethnography: Challenges for Research in Large Scale Online Environments. In Proceedings of the 2012 iConference, 207-214. doi: 10.1145/2132176.2132203 [GS Search]

Saha, A., \& Agarwal, N. (2015). Demonstrating social support from autism bloggers community on twitter. In Proceedings of IEEE/ACM International Conference on Advances in Social Networks Analysis and Mining (ASONAM), 1053-1056. doi: $\underline{10.1145 / 2808797.2809364 \text { [GS Search] }}$

Salminen, J., Santos, J. M., Kwak, H., An, J., Jung, S. G., \& Jansen, B. J. (2020). Persona Perception Scale: Development and Exploratory Validation of an Instrument for Evaluating Individuals' Perceptions of Personas. International Journal of HumanComputer Studies, 141, 102437. doi: 10.1016/j.ijhcs.2020.102437 [GS Search]

Silva, F., Marques, A., \& Figueiredo, T. (2021). Um estudo comparativo na geração de personas de crianças autistas com base em dados reais. In Anais do VI Workshop sobre Aspectos Sociais, Humanos e Econômicos de Software, (pp. 21-30). Porto Alegre: SBC. doi: 10.5753/washes.2021.15886 [GS Search]

Uchoa, A., \& Coutinho, E. (2018). De que Forma a Cultura do Compartilhamento e Modificação pode Colaborar no Processo de Desenvolvimento de Jogos?. In Anais do III Workshop sobre Aspectos Sociais, Humanos e Econômicos de Software, 1-5. doi:10.5753/washes.2018.3475 [GS Search] 